\title{
Development of a Fuzzy Slip Control System for Electric Vehicles with In-wheel Motors
}

\author{
Kiumars Jalali, Thomas Uchida, John McPhee and Steve Lambert \\ Univ of Waterloo
}

\begin{abstract}
A two-passenger all-wheel drive urban electric vehicle (AUTO21EV) with four direct-drive in-wheel motors and an active steering system has been designed and developed at the University of Waterloo. A novel fuzzy slip control system is developed for this vehicle using the advantage of four in-wheel motors. A conventional slip control system uses the hydraulic brake system in order to control the tire slip ratio, which is the difference between the wheel center velocity and the velocity of the tire contact patch along the wheel plane, thereby influencing the longitudinal dynamics of a vehicle.

The advantage of the proposed fuzzy slip controller is that it acts as an ABS system by preventing the tires from locking up when braking, as a TCS by preventing the tires from spinning out when accelerating. More importantly, the proposed slip controller is also capable of replacing the entire hydraulic brake system of the vehicle by automatically distributing the braking force between the wheels using the available braking torque of the in-wheel motors. In this regard, the proposed fuzzy slip controller guarantees the highest traction or braking force on each wheel on every road condition by individually controlling the slip ratio of each tire with a much faster response time. The performance of the proposed fuzzy slip controller is confirmed by driving the AUTO21EV through several test maneuvers using a driver model in the simulation environment. As the final step, the fuzzy slip controller is implemented in a hardware- and operator-in-the-loop driving simulator and its performance and effectiveness is confirmed.
\end{abstract}

CITATION: Jalali, K., Uchida, T., McPhee, J. and Lambert, S., "Development of a Fuzzy Slip Control System for Electric Vehicles with In-wheel Motors," SAE Int. J. Alt. Power. 1(1):2012, doi:10.4271/2012-01-0248.

\section{INTRODUCTION}

In the last 30 years, advances in electronics have revolutionized many aspects of the automobile industry. Areas like engine management and safety systems, such as anti-lock braking systems (ABS), traction control systems (TCS), and electronic stability control (ESC) systems, have received particular attention. These safety systems involve the use of electronic control units to modulate the brake and accelerator pedal inputs provided by the driver in order to control the slip of individual tires during emergency braking (ABS) or accelerating (TCS), or to control the stability of the vehicle by braking individual wheels (ESC) [ $\underline{\text { Zan00, }}, \underline{\text { Alb96}}$, Ack99].

ABS is by no means a new innovation, and its development and acceptance has occurred over a number of decades. The first ABS system was developed by Dunlop Maxaret in 1952, and was used on aircraft landing systems [Vel01]. In 1978, Robert Bosch GmbH introduced the modern anti-lock braking system for passenger vehicles [Mar02-a, Mar02-b]. By the 1990s, ABS was a common option on many vehicles, and is now a standard feature, or at least an optional feature, on nearly all new vehicles. In 1971, the Buick division of GM introduced MaxTrac as the first TCS, which was used to detect rear wheel spin and modulate the engine power delivered to those wheels in order to provide the most traction possible. Since then, more sophisticated TCS systems have been developed by different companies, such as Cadillac and Robert Bosch $\mathrm{GmbH}$, and involve an engine management controller that cooperates with the brake system in order to prevent the driven wheels from spinning out. A comprehensive overview of the history, operation, and types of slip control systems can be found in [Bur93].

The primary task of a slip control system, such as ABS or TCS, is to influence the longitudinal dynamics of a vehicle by preventing the tires from locking up when braking or spinning out when accelerating, thereby enhancing the directional stability of the vehicle. According to a study conducted by the Monash University Accident Research Centre, ABS has reduced the risk of multiple vehicle crashes by $18 \%$ and the risk of run-off-road crashes by $35 \%$ [Bur04]. Another study conducted by the National Highway Traffic 
Safety Administration (NHTSA) confirms that a statistically significant decrease in multi-vehicle crashes and fatal pedestrian strikes is achievable using the ABS system [Maz01]. As a result, the European Automobile Manufacturers Association has been committed to equipping all new vehicles with ABS since 2003 [Bur04]. Figures from the United States suggested that about $95 \%$ of new vehicles were equipped with ABS in 2003 [Vel01].

Recently, electric vehicles (EVs) have attracted a great deal of interest as an elegant solution to environmental and energy concerns. Among other benefits, EVs have a better efficiency and can eliminate or reduce the environmental noise and pollutants that are associated with the conventional internal combustion engines (ICE) considerably. Also, thanks to substantial improvements in electric motor and battery technologies, EVs now have driving performance metrics that are comparable to those of ICE vehicles. In addition, EVs are the most exciting platforms on which to apply advanced motion control techniques, since the motor torque and speed can be generated and controlled much quicker and more accurately than any ICE or even hydraulic brake systems.

Figure 1 illustrates the AUTO21EV, which is a twopassenger all-wheel-drive urban electric vehicle developed and modelled in this work using the ADAMS/View environment. This vehicle has a similar configuration to the commercially available Smart fortwo, but it is equipped with four direct-drive in-wheel motors and an active steering system on the front axle. Table 1 lists some of the relevant parameters used in the AUTO21EV model. The use of small but powerful direct-drive in-wheel motors allows for the implementation of the most advanced all-wheel-drive system in which the optimal traction force can be generated on each tire by controlling the tire slip at all times.

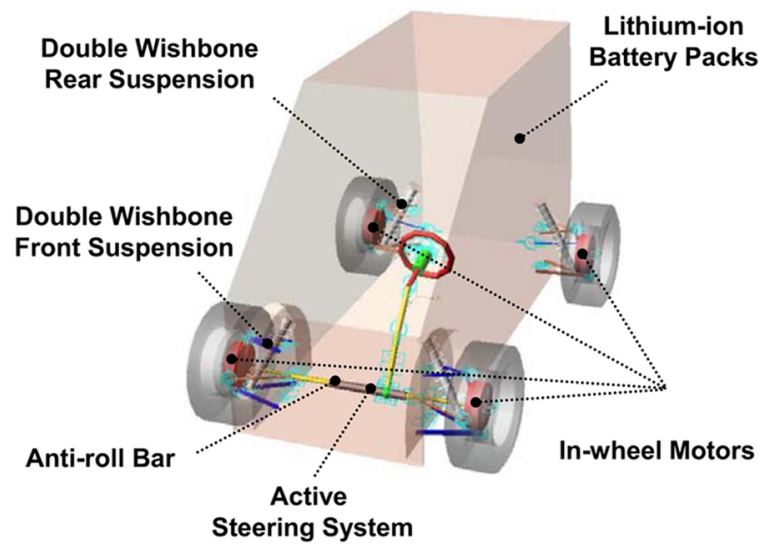

Figure 1. AUTO21EV concept vehicle

\section{INTEGRATION OF IN-WHEEL MOTORS WITH VEHICLE MODEL}

The in-wheel motors used in the AUTO21EV are directdrive permanent magnet synchronous motors (PMSM). This implies that no gear reduction is used between the motor and the drive shaft, which reduces the weight and size of the system, but also requires that the speed-torque characteristics of the motors meet the requirements of the vehicle. These PMSM motors are designed upside-down, meaning that the rotor is the rotating external part, which can also be attached to the rim, and the stator is attached to the wheel shaft. This approach is primarily used to reduce the moment of inertia of the rotating parts, thereby reducing the amount of energy required to stop or accelerate the wheels. In addition, fluxweakening techniques have been used to increase the performance and efficiency of the motors by eliminating the magnetization loss in the field of the motors. Balanced sinusoidal three-phase current is enforced in the stator to achieve synchronous operation and smooth torque profile. Although these characteristics are usually achieved using an inverter by establishing pulse-width-modulation (PWM) control, the switching effects have been neglected here for simplicity and it is assumed that the PWM works like an ideal three-phase variable voltage source. Moreover, saturation, eddy currents, hysteresis losses, and field current dynamics have also been neglected for simplicity of the model. Altogether, five parameters are identified for the motor model: the phase resistance, the magnetic flux linkage, two phase inductances, and the number of magnetic poles. In addition, two state variables are used to define the dynamic characteristics of the motors - specifically, the time derivatives of the currents of the two-phase system. The three-phase voltages are the inputs to the motor model and the motor torque is the output of the plant. The angle and angular velocity of the wheels are state variables of the vehicle model and are treated as external parameters. Further details about the PMSM motor models and the corresponding motor controllers used in this work can be found in [Vog09]. Table 2 lists the parameters of the in-wheel motors used in this work.

Table 1. AUTO21EV model parameters

\begin{tabular}{|l|c|c|}
\hline Parameter & Value & Unit \\
\hline Vehicle mass $(\mathrm{M})$ & 1075 & $\mathrm{~kg}$ \\
\hline Vehicle yaw moment of inertia $\left(\mathrm{I}_{\mathrm{zz}}\right)$ & 1171 & $\mathrm{~kg} \mathrm{~m}$ \\
\hline Distance from CG to front axle $(\mathrm{a})$ & 0.82 & $\mathrm{~m}$ \\
\hline Distance from CG to rear axle $(\mathrm{b})$ & 0.98 & $\mathrm{~m}$ \\
\hline Front track width $\left(\mathrm{t}_{\mathrm{f}}\right)$ & 1.275 & $\mathrm{~m}$ \\
\hline Rear track width $\left(\mathrm{t}_{\mathrm{r}}\right)$ & 1.35 & $\mathrm{~m}$ \\
\hline Front tire cornering stiffness $\left(\mathrm{C}_{\alpha \mathrm{f}}\right)$ & 45570 & $\mathrm{~N} / \mathrm{rad}$ \\
\hline Rear tire cornering stiffness $\left(\mathrm{C}_{\mathrm{ar}}\right)$ & 45570 & $\mathrm{~N} / \mathrm{rad}$ \\
\hline Tire size & $175 / 55 \mathrm{R} 15$ & - \\
\hline Tire unloaded radius $(\mathrm{r})$ & 0.29 & $\mathrm{~m}$ \\
\hline
\end{tabular}


Table 2. In-wheel motor parameters

\begin{tabular}{|l|c|c|}
\hline Specification & Value & Unit \\
\hline Maximum power & 25 & $\mathrm{~kW}$ \\
\hline Peak torque & 300 & $\mathrm{Nm}$ \\
\hline Maximum speed (no load) & 3200 & $\mathrm{rpm}$ \\
\hline Maximum voltage & 315 & $\mathrm{~V}$ \\
\hline Maximum current & 300 & $\mathrm{~A}$ \\
\hline Total mass & 30 & $\mathrm{~kg}$ \\
\hline Rotor mass & 11.2 & $\mathrm{~kg}$ \\
\hline Magnetic flux $(B)$ & 0.4 & $\mathrm{~V} / \mathrm{rad} / \mathrm{s}$ \\
\hline Phase inductance $\left(\mathrm{L}_{\mathrm{s}}\right)$ & 6 & $\mathrm{mH}$ \\
\hline Phase resistance $\left(\mathrm{R}_{\mathrm{s}}\right)$ & 1.653 & $\Omega$ \\
\hline Number of pole pairs & 10 & - \\
\hline
\end{tabular}

\section{CONVENTIONAL SLIP CONTROL SYSTEMS}

Conventional slip control systems on the market use the hydraulic brake system and/or the engine management controller in order to control the tire slip, thereby influencing the longitudinal dynamics of the vehicle. Slip control systems are closed-loop control devices that prevent tire lock-up and spin-out during braking and acceleration, respectively. In a closed-loop control system, the measured response of a physical system is compared to a desired response, and the difference between the two initiate actions that will cause the actual response of the system to approach the desired response.

An ABS system detects the onset of wheel lockup due to a high braking force, and then limits the braking pressure to prevent wheel lockup. An ABS system is considered a standalone system (it can be installed independently of other control systems), and consists of a wheel speed sensor, a hydraulic modulator, and an electronic control unit (ECU) for signal processing, control, and triggering the actuators in the hydraulic modulator [Bos07]. The ECU recognizes wheel lockup by detecting sharp increases in wheel deceleration, and reduces the braking force in a closed-loop process until the lockup situation vanishes. The cyclic application and reduction of the braking force ensures that the brakes operate at or near their most efficient operating point and the vehicle maintains steering control. In general, when a driver presses the brake pedal, the brake slip increases until the point of maximum friction between the tire and the road is reached, which is the limit between the stable and unstable regions. At this point, any increase in brake pressure will reduce the friction force between the tire and the road and the wheel tend towards skidding. In a vehicle with a conventional braking system, as the wheels tend towards lockup, the lateral force potential of the tires that enables steering is greatly reduced, and approaches zero when the wheels are fully locked. By preventing wheel lockup, however, the lateral force potential of the tires is maintained at a high level, allowing the driver to retain steering control during emergency braking. Therefore, the task of an ABS system is to use the friction coefficient between the tires and the road surface in an optimal fashion in order to minimize the braking distance while retaining steerability.

Tire slip can also be controlled in an acceleration mode using a combination of the hydraulic brake system and the engine management controller to prevent tire spin-out. This task is accomplished by a TCS system, which is a constructive add-on to an existing ABS system and cannot be installed alone. In a TCS, the ECU recognizes wheel spin-out by detecting sharp increases in wheel acceleration. The ECU then reduces the engine torque through the engine management controller in a closed-loop process to reduce the traction force on the driven wheels. If the ECU was unable to prevent a spinout situation using this first method of intervention, it operates the brakes in order to stop the wheel from spinning out. The cyclic application and the cooperation between the engine management controller and the brake system together ensure that the friction coefficient between the tires on the driven wheels and the road surface is used in an optimal fashion, maximizing the traction force while retaining stability and steerability. Note that the aim of a TCS system is defined based on the vehicle configuration. In a front-wheel-drive (FWD) vehicle, TCS aims to maximize the traction force while retaining steerability, whereas in a rearwheel-drive (RWD) vehicle, TCS intends to maintain vehicle stability while maximizing the traction force.

\section{METHODS OF ADJUSTING THE SLIP RATIO}

One method of adjusting the tire slip ratio in a slip control system is to limit the maximum possible slip ratio to a fixed amount. This strategy is shown in Figure 2, where the longitudinal force $\left(\mathrm{F}_{\mathrm{x}}\right)$ and lateral force $\left(\mathrm{F}_{\mathrm{y}}\right)$ of the tire are plotted as functions of the longitudinal slip ratio of the tire [Bei00]. The bold vertical line in Figure 2 highlights the limited slip ratio control strategy. The advantage of this method is that the tire slip angle $(\alpha)$ reasonably controls the relation between the longitudinal and lateral tire forces. In other words, at a fixed slip ratio, when the tire slip angle increases, the longitudinal tire force decreases and, at the same time, the lateral force potential of the tire increases, which improves the lateral stability of the vehicle.

An alternative approach is to adjust the tire slip ratio such that the maximum possible traction force can be generated at all slip angles. This method prioritizes the longitudinal tire force over the lateral tire force and ensures that the maximum possible traction force is attained at every sideslip angle [Bei00]. In other words, if the tire slip ratio is adjusted such that the maximum longitudinal force can be generated when the tire slip angle increases, the lateral force potential will not always increase. This situation is shown in Figure 3 , where the upper bold-dashed line indicates the peak tire forces in the longitudinal direction at every slip angle, and the lower bold- 


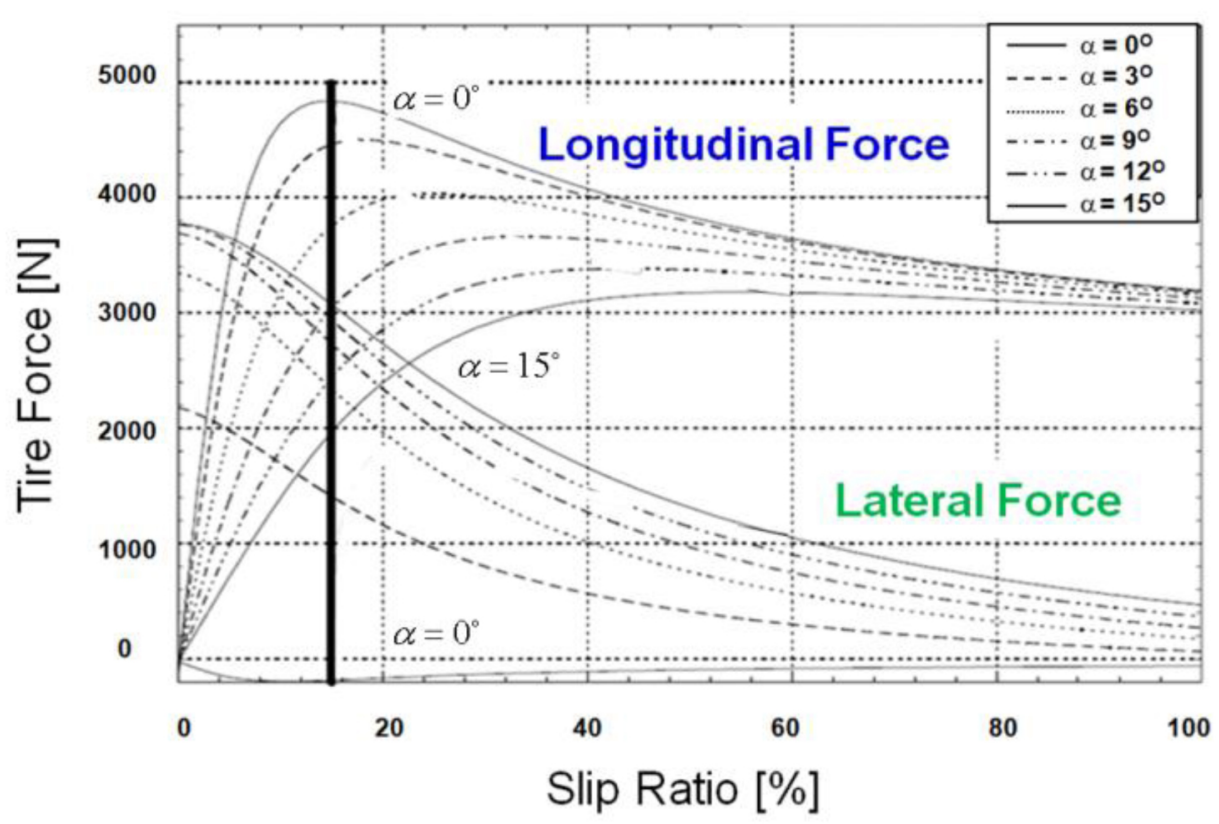

Figure 2. Characteristics of the tire longitudinal and lateral forces as a function of tire slip ratio for constant tire slip angles; used for a slip control system with limited slip ratio [Bei00]

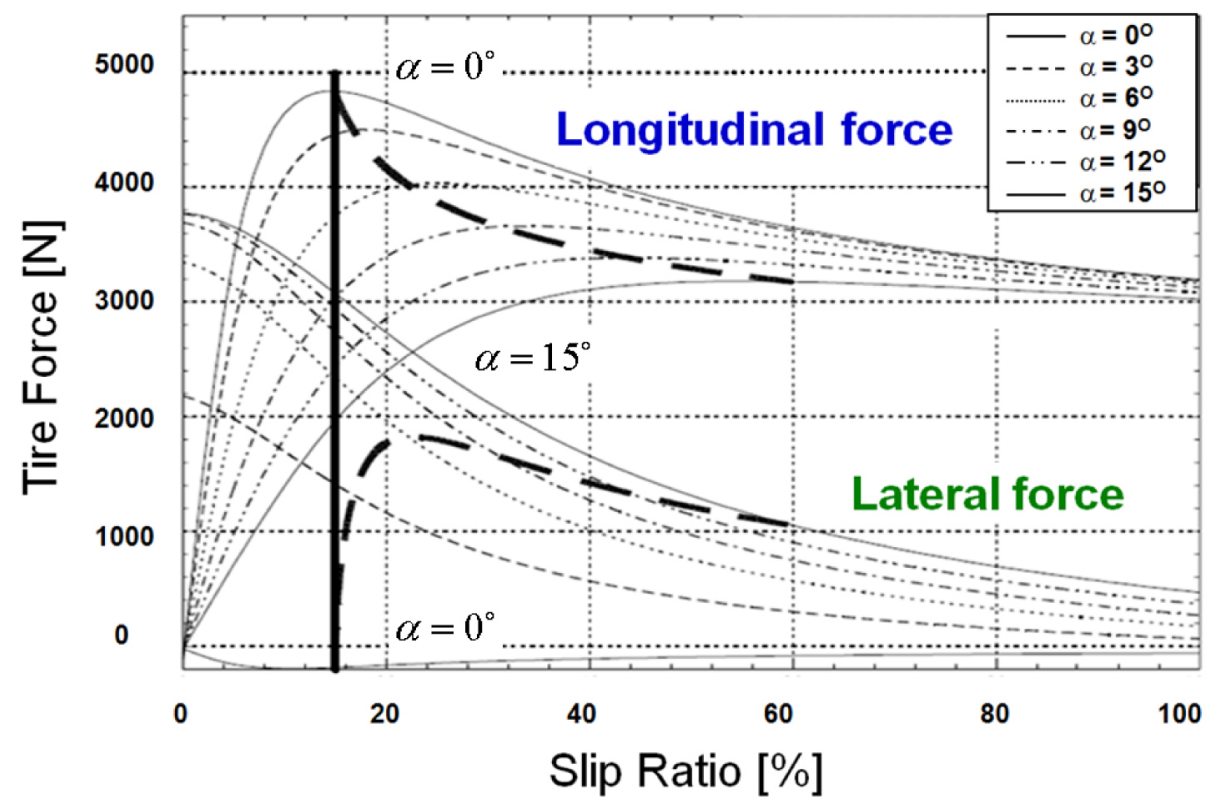

Figure 3. Characteristics of the tire longitudinal and lateral forces as a function of tire slip ratio for constant tire slip angles; used for a slip control system with adjustable slip ratio [Bei00]

dashed line indicates the corresponding lateral force of the tire.

\section{DEVELOPMENT OF AN ADVANCED FUZZY SLIP CONTROL SYSTEM}

As explained earlier, the tire slip ratio can be controlled either by limiting the maximum possible slip ratio to a fixed amount or by adjusting the tire slip ratio such that the maximum possible traction force can be generated at all slip angles. On the other hand, the adhesion coefficient versus tire slip ratio plot shown in Figure 4 suggests that the maximum adhesion coefficient for different road conditions can be generated at a slip ratio of about $15 \%$. Although this limit closely corresponds to the position of the peak adhesion coefficient for a dry road condition, the descending slopes associated with other road conditions are small up to this slip 


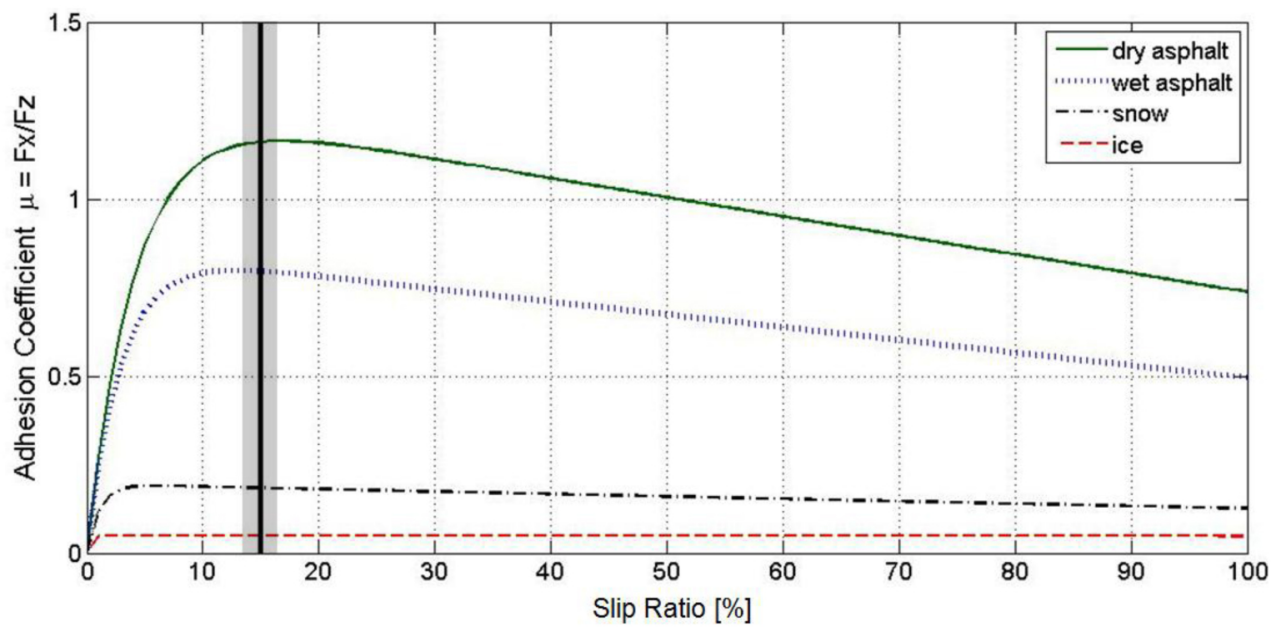

Figure 4. Typical adhesion coefficient characteristics as a function of tire slip ratio for different road conditions

limit; thus a slip ratio of $15 \%$ can be considered to represent the maximum traction at other road conditions as well. With this in mind, and noting that higher vehicle stability is more advantageous than maximum traction when driving in a curve, the limited tire slip ratio method has been chosen for the advanced fuzzy slip controller of the AUTO21EV.

The actual slip ratio of each tire is calculated as a positive number using the following equations for brake and acceleration modes, respectively:

$$
\begin{aligned}
\lambda_{\text {brake }, i}= & \frac{v_{w, x_{i}^{\prime}}-\omega_{w, i} r_{d y n, i}}{v_{w, x_{i}^{\prime}}} \text { if } v_{w, x_{i}^{\prime}} \geq 0, \omega_{w, i} \geq 0, \\
& \text { and } \omega_{w, i} r_{d y n, i} \leq v_{w, x_{i}^{\prime}} \\
\lambda_{\text {accel }, i}= & \frac{\omega_{w, i} r_{d y n, i}-v_{w, x_{i}^{\prime}}}{\omega_{w, i} r_{d y n, i}} \text { if } v_{w, x_{i}^{\prime}} \geq 0, \omega_{w, i} \geq 0, \\
& \text { and } \omega_{w, i} r_{d y n, i} \geq v_{w, x_{i}^{\prime}}
\end{aligned}
$$

where $i \epsilon\{\mathrm{FL}, \mathrm{FR}, \mathrm{RL}, \mathrm{RR}\},{ }_{w, x_{i}^{\prime}}$ is the speed of the wheel center along the wheel plane, $r_{d y n}$ is the dynamic tire radius, and $\omega_{\mathrm{w}}$ is the angular velocity of the tire. It is important to note that, although all of the variables mentioned above are accessible in a simulation environment, they must be measured or estimated in real life. The dynamic tire radius, which is also known as the effective tire radius, is the ratio of the linear velocity of the wheel center in the longitudinal direction to the angular velocity of the wheel [Blu04]. Although the dynamic tire radius has to be estimated in real life, in this work for simplicity, the calculated dynamic tire radius is deployed directly from the tire model at each time step. Note that the static loaded tire radius, which is the loaded radius of a stationary tire inflated to the normal recommended pressure, is also used in the literature, but it is associated with some inaccuracy [Bei00, Kie05]. If the vehicle travels in a straight line and the tires roll freely without skidding and without any torque applied to them, the speed of the wheel center along the wheel plane is equivalent to the speed of the center of gravity of the vehicle. In the presence of simultaneous longitudinal and lateral wheel slips, however, the wheel center speeds are estimated by transferring the vehicle velocity $\left(\vec{v}_{C G}\right)$ to the wheel centers [Kie05]. Figure 5 illustrates a two-track model of the vehicle in the horizontal plane, which can be used to calculate the wheel speeds. The vehicle velocity $\vec{v}_{C G}$ and the magnitudes of the longitudinal $a_{C G, x}$ and lateral $a_{C G, y}$ accelerations are calculated as follows:

$$
\begin{gathered}
\vec{v}_{C G}=v_{C G, x} \cdot \vec{e}_{x}+v_{C G, y} \cdot \vec{e}_{y} \\
a_{C G, x}=\dot{v}_{C G, x}-v_{C G, y} \cdot \dot{\psi} \\
a_{C G, y}=\dot{v}_{C G, y}+v_{C G, x} \cdot \dot{\psi}
\end{gathered}
$$

where $\vec{e}_{x}$ and $\vec{e}_{y}$ are unit vectors along the longitudinal and lateral axes of the vehicle, respectively, $v_{C G, x}$ and $v_{C G, y}$ are the longitudinal and lateral speeds of the vehicle, and $\dot{\psi}$ is the vehicle yaw rate. In real life, the longitudinal $\left(\dot{v}_{C G, x}\right)$ and lateral $\left(\dot{v}_{C G, y}\right)$ accelerations of the vehicle are measured with two accelerometers, which are positioned at or near the center of mass of the vehicle along the longitudinal and lateral vehicle axes, respectively. The yaw rate $\dot{\psi}$ is measured using a gyroscope positioned at the center of gravity of the vehicle, along its vertical axis. It is important to note that, in real life, 
the vehicle velocity $\left(\vec{v}_{C G}\right)$ must be estimated as well. Three common methods of estimating the vehicle velocity are as follows [ie05, Bos07]:

- Transforming the measured wheel speeds to the center of gravity of the vehicle and fusing the data from all rotational wheel speeds with the integrated longitudinal acceleration signal,

- using a Kalman filter, and

- using a fuzzy estimator.

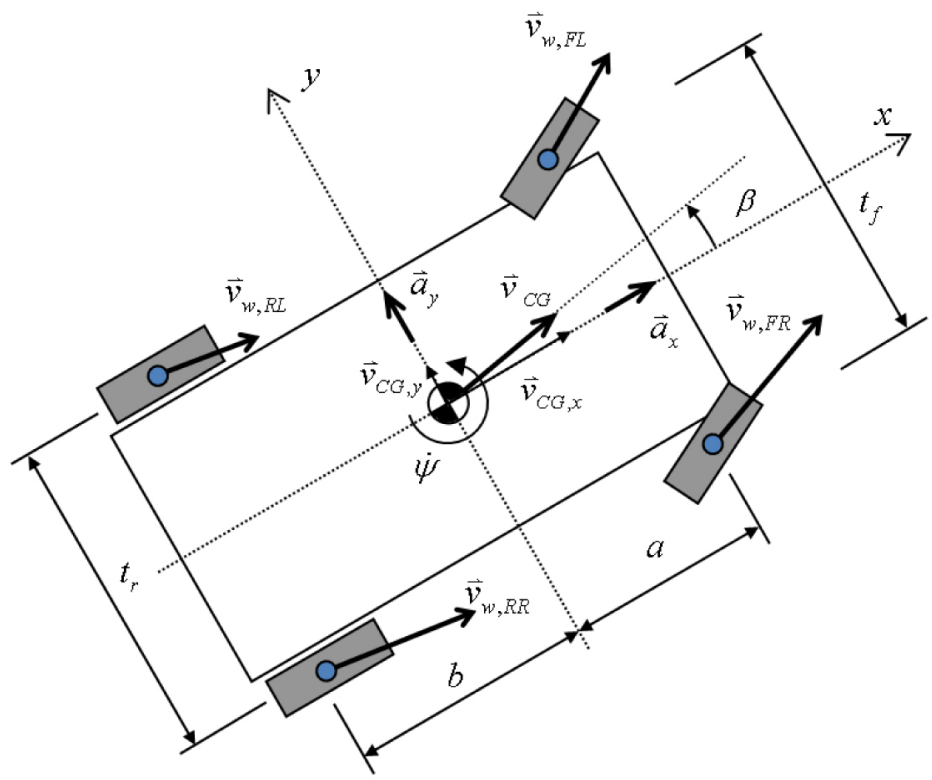

Figure 5. Planar two-track vehicle model

In this work, however, for the sake of accuracy and simplicity, the vehicle velocity is obtained directly from the simulation environment and is not estimated. Moreover, the sideslip angle $(\beta)$ of the vehicle, which is the angle between the direction of motion of the vehicle and its longitudinal axis, cannot be measured directly using a sensor. In this work, a neural network similar in structure to that proposed by Durali and Bahramzadeh [Dur03] is used to estimate this angle. Knowing the sideslip angle of the vehicle, the longitudinal and lateral speeds of the vehicle are calculated as follows:

$$
\begin{aligned}
& v_{C G, x}=v_{C G} \cdot \cos (\beta) \\
& v_{C G, y}=v_{C G} \cdot \sin (\beta)
\end{aligned}
$$

Looking at Figure 5, the wheel center velocities $\vec{v}_{w, i}$ can be calculated as follows [Kie05]:

$$
\vec{v}_{w, F L}=\left(v_{C G, x}-\dot{\psi} \cdot \frac{t_{f}}{2}\right) \vec{e}_{x}+\left(v_{C G, y}+\dot{\psi} \cdot a\right) \vec{e}_{y}
$$

$$
\begin{aligned}
& \vec{v}_{w, F R}=\left(v_{C G, x}+\dot{\psi} \cdot \frac{t_{f}}{2}\right) \vec{e}_{x}+\left(v_{C G, y}+\dot{\psi} \cdot a\right) \vec{e}_{y} \\
& \vec{v}_{w, R L}=\left(v_{C G, x}-\dot{\psi} \cdot \frac{t_{r}}{2}\right) \vec{e}_{x}+\left(v_{C G, y}-\dot{\psi} \cdot b\right) \vec{e}_{y} \\
& \vec{v}_{w, R R}=\left(v_{C G, x}+\dot{\psi} \cdot \frac{t_{r}}{2}\right) \vec{e}_{x}+\left(v_{C G, y}-\dot{\psi} \cdot b\right) \vec{e}_{y}
\end{aligned}
$$

Note that the wheel center velocities are calculated with respect to the local coordinate system of the vehicle. According to equations (1) and (2), the slip ratio of a tire is calculated along the wheel plane. Since the rear wheels of AUTO21EV do not steer, their local coordinate systems are parallel to the vehicle coordinate system. Thus, the portion of the wheel center velocity along the $\mathrm{x}$-axis from equations (10) and (11) can be used directly to calculate the wheel slip for the rear tires:

$$
\begin{aligned}
& v_{w, x_{R L}}=v_{w, x_{R L}^{\prime}}=v_{C G, x}-\dot{\psi} \cdot \frac{t_{r}}{2} \\
& v_{w, x_{R R}}=v_{w, x_{R R}^{\prime}}=v_{C G, x}+\dot{\psi} \cdot \frac{t_{r}}{2}
\end{aligned}
$$

Note that $v_{w, x_{R L}^{\prime}}$ and $v_{w, x_{R R}^{\prime}}$ indicate the wheel center velocities of the rear-left and rear-right tires with respect to the local coordinate systems of the wheels. The local coordinate systems of the front wheels are rotated by the steering angle $\delta$, so equations (8) and (9) must be transformed into the appropriate wheel coordinate systems. Looking at Figure 6, the wheel center velocities of the front wheels can be calculated as follows:

$$
v_{w, x_{F L}^{\prime}}=\left(v_{C G, x}-\dot{\psi} \cdot \frac{t_{f}}{2}\right) \cdot \cos (\delta)+\left(v_{C G, y}+\dot{\psi} \cdot a\right) \cdot \sin (\delta)
$$

$$
v_{w, x_{F R}^{\prime}}=\left(v_{C G, x}+\dot{\psi} \cdot \frac{t_{f}}{2}\right) \cdot \cos (\delta)+\left(v_{C G, y}+\dot{\psi} \cdot a\right) \cdot \sin (\delta)
$$

As mentioned earlier, one advantage of the AUTO21EV is that both ABS and TCS systems can be realized through the available in-wheel motors without using the conventional brake system or engine management controller. The torque 

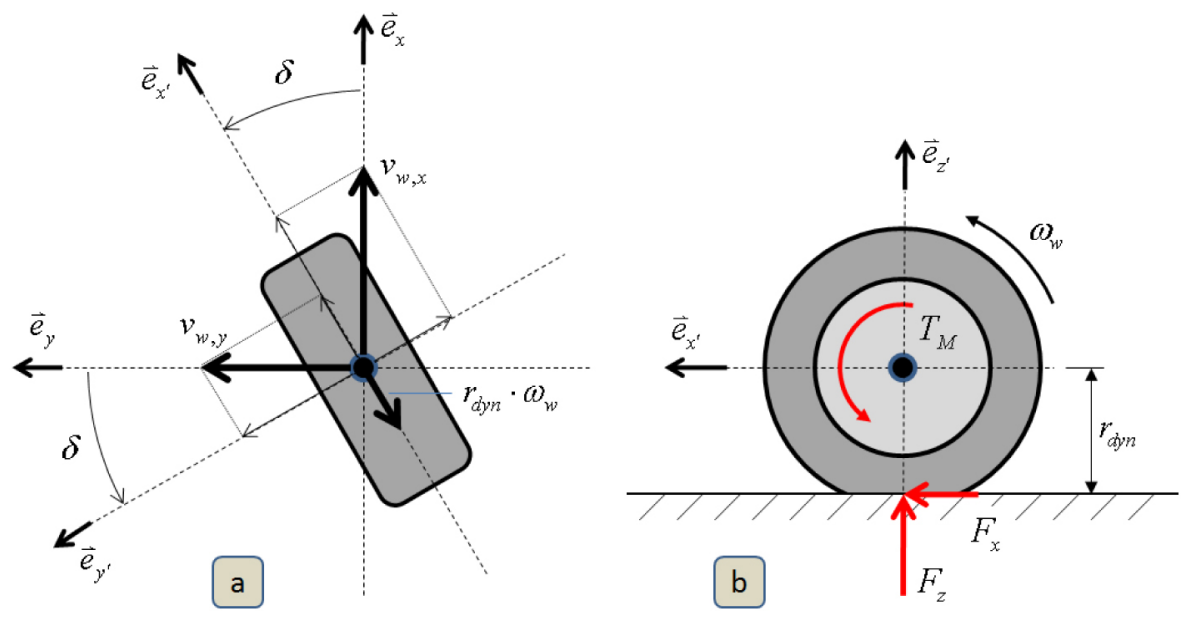

Figure 6. (a) Translational and (b) rotational tire motion

response of an electric motor is several milliseconds, which is 10 to 100 times faster than that of an internal combustion engine or even a hydraulic brake system [Hor04]. When coupled with the ability to individually control the wheel slip at each corner of the vehicle, this platform has allowed us to design a very advanced slip control system for the AUTO21EV using its in-wheel motors.

Fuzzy logic control systems are robust and flexible inference methods that are well suited for tackling complicated nonlinear dynamic control problems. As such, they are ideal candidates for controlling the highly nonlinear behavior inherent in vehicle dynamics. Fuzzy control systems can tolerate imprecise information and can describe expert knowledge in vague linguistic terms, which suits the subjective nature of vehicle dynamics and slip control systems [Kar04]. The rule base of the fuzzy slip controller was designed using the slip ratio error $\dot{e}(\lambda)$ and the rate of change of the slip ratio error $\dot{e}(\lambda)$ as the inputs; the corrective motor torque $\mathrm{T}_{\text {corr }}$ is the output of the slip controller (see Table 3). The tire slip ratio error is calculated by comparing the actual tire slip with the desired slip limit at every time step. The rate of change of the slip ratio error is calculated by subtracting the previous slip ratio error from the current one, and dividing the result by the sample time of the controller. The controller inputs and output are normalized to simplify the definition of the fuzzy sets. Four and seven fuzzy sets are used for the slip ratio error and the rate of change of the slip ratio error, respectively, in order to provide enough rule coverage. Nine fuzzy sets are used to describe the output of the fuzzy slip controller.
Table 3. Definition of the input and output variables of the fuzzy slip controller

\begin{tabular}{|c|c|}
\hline Variable & Definition \\
\hline Input 1 & $\mathrm{e}(\lambda)=\lambda_{\text {lim }}-\lambda_{\text {act }}$ \\
\hline Input 2 & $\dot{\mathrm{e}}(\lambda)=\frac{\mathrm{e}(\lambda)_{\mathrm{k}}-\mathrm{e}(\lambda)_{\mathrm{k}-1}}{\text { sample time }}$ \\
\hline Output & $\mathrm{T}_{\text {corr }}$ \\
\hline
\end{tabular}

The fuzzy inference system processes the list of rules in the knowledge base using the fuzzy inputs obtained from the previous time step of the simulation, and produces the fuzzy output which, once defuzzified, is applied in the next time step. The Mamdani fuzzy inference method is used, which is characterized by the following fuzzy rule schema:

$$
\text { IF e }(\lambda) \text { is } A \text { AND } \dot{\mathrm{e}}(\lambda) \text { is } B \text { THEN T } \mathrm{T}_{\text {corr }} \text { is } C
$$

where $\mathrm{A}, \mathrm{B}$, and $\mathrm{C}$ are fuzzy sets defined on the input and output domains. The control rule base of the proposed fuzzy slip controller is developed based on expert knowledge and extensive investigation. Figure 7 illustrates the control rule base and control surface of the fuzzy slip controller. The linguistic terms that have been used in this table are listed in Table 4. The shape and distribution of the membership functions used for the input and output variables of the fuzzy slip controller are shown in Figure 8. Since only positive membership functions have been used for $\mathrm{e}(\lambda)$ and the slip controller is only activated when $\mathrm{e}(\lambda)$ is negative (i.e., when the actual slip ratio of a tire is greater than the slip limit), the slip ratio error must be converted into a positive number before entering the fuzzy slip controller. This procedure is 


\begin{tabular}{|c|c|c|c|c|c|}
\hline \multirow{2}{*}{\multicolumn{2}{|c|}{$\begin{array}{c}\text { Control } \\
\text { Rule Base }\end{array}$}} & \multicolumn{4}{|c|}{$e(\lambda)$} \\
\hline & & \multirow{2}{*}{$\begin{array}{l}\text { ZE } \\
Z E\end{array}$} & \multirow{2}{*}{$\begin{array}{l}\text { PS } \\
Z E\end{array}$} & \multirow{2}{*}{$\begin{array}{c}\text { PM } \\
Z E\end{array}$} & \multirow{2}{*}{$\begin{array}{l}\text { PL } \\
Z E\end{array}$} \\
\hline \multirow{7}{*}{$\overbrace{-\infty}^{\infty}$} & NL & & & & \\
\hline & NM & ZE & ZE & ZE & NS \\
\hline & NS & ZE & ZE & NS & NM \\
\hline & ZE & ZE & NS & NM & NL \\
\hline & PS & NM & NL & NVL & NVL \\
\hline & PM & NL & NVL & NVL & NVL \\
\hline & PL & NVL & NVL & NVL & NVL \\
\hline
\end{tabular}

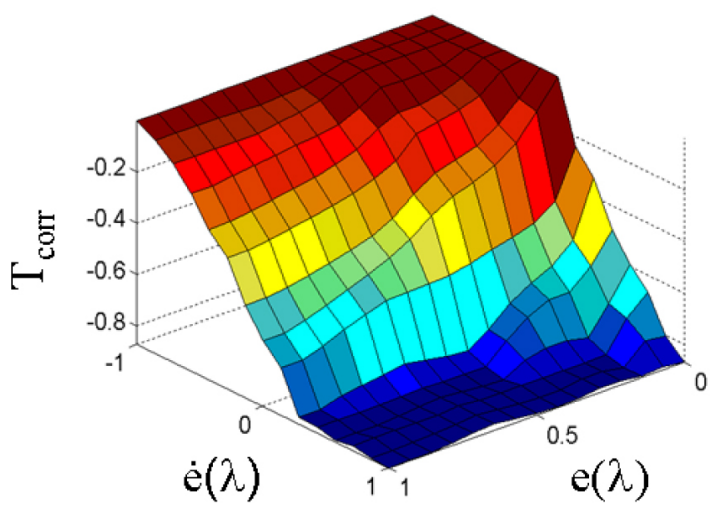

Figure 7. Control rule base (left) and control surface (right) of the fuzzy slip control system
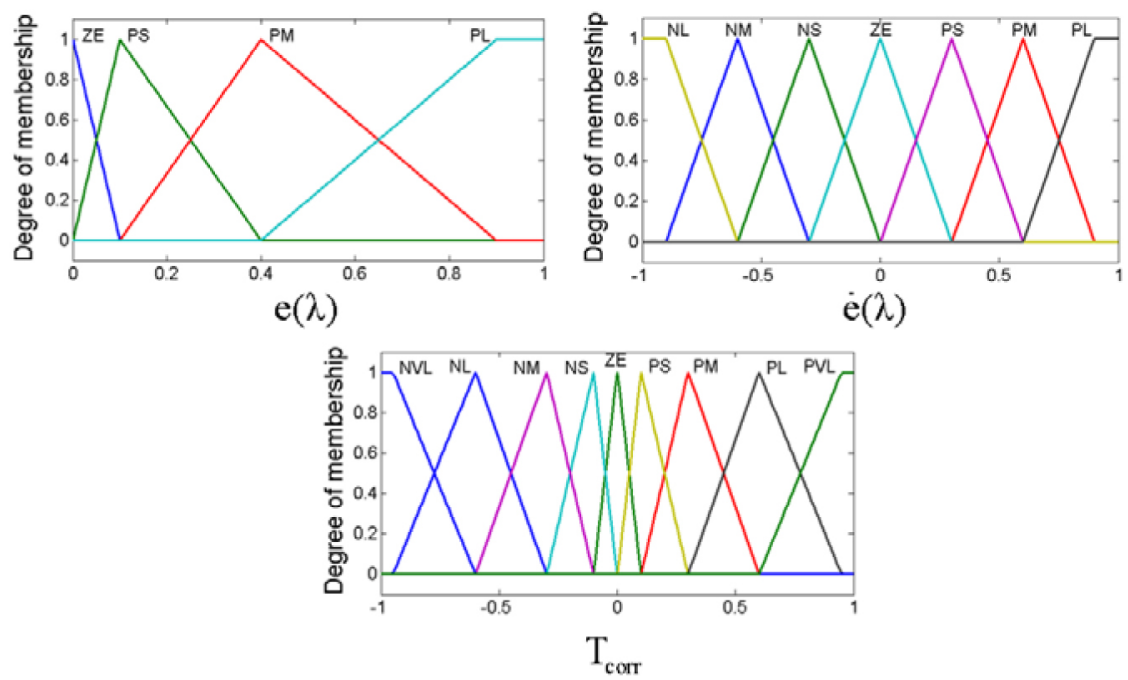

Figure 8. Shape and distribution of membership functions for the input and output variables of the fuzzy slip controller

shown in Figure 9, where the block diagram of the entire slip control system is illustrated.

\section{EVALUATION OF THE ADVANCED FUZZY SLIP CONTROL SYSTEM}

The performance of the fuzzy slip controller is tested using four different maneuvers. First, the AUTO21EV is accelerated in a straight line from $5 \mathrm{~km} / \mathrm{h}$ to its maximum speed of $90 \mathrm{~km} / \mathrm{h}$. The acceleration starts at 0.5 seconds into the simulation and the vehicle reaches its maximum speed after 5 seconds (Figure 10-a). As illustrated in Figure 10-b, a maximum acceleration of about $0.85 \mathrm{~g}$ is achievable up to a speed of $28 \mathrm{~km} / \mathrm{h}$, where the maximum motor torques are available.
Table 4. Linguistic variables used in the fuzzy rules

\begin{tabular}{|c|c|}
\hline Acronym & Linguistic Variable \\
\hline NVL & Negative Very Large \\
\hline NL & Negative Large \\
\hline NM & Negative Medium \\
\hline NS & Negative Small \\
\hline ZE & Zero \\
\hline PS & Positive Small Medium \\
\hline PM & Positive Large \\
\hline PL & Positive Very Large \\
\hline PVL &
\end{tabular}




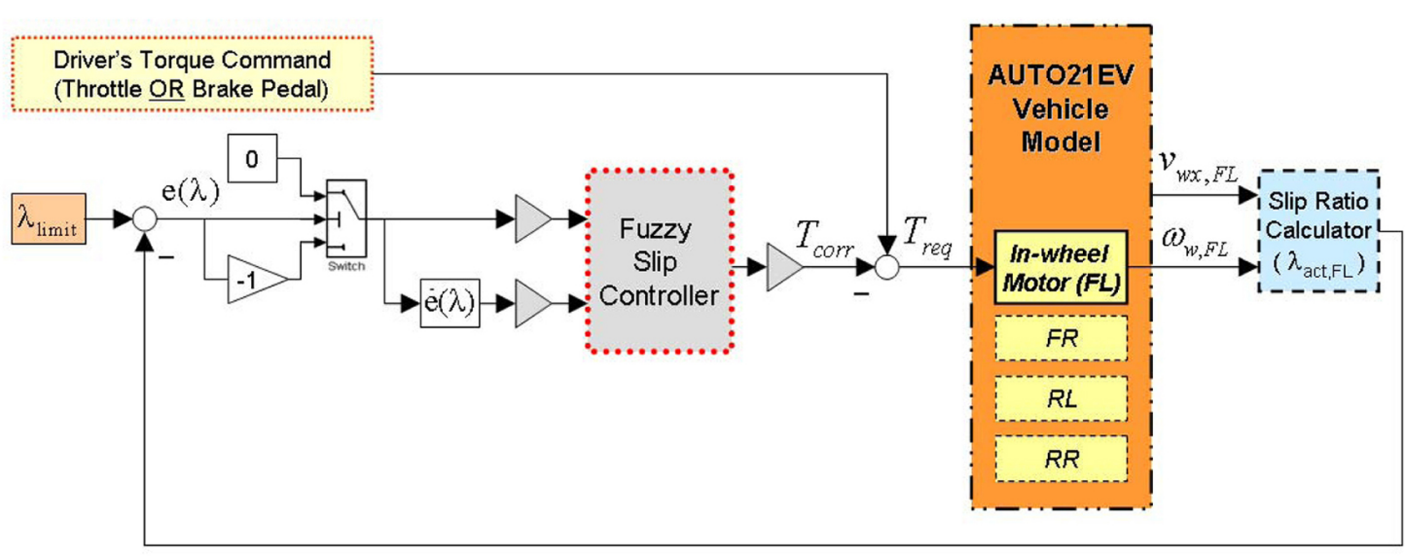

Figure 9. Block diagram of the advanced slip control system for the front-left tire
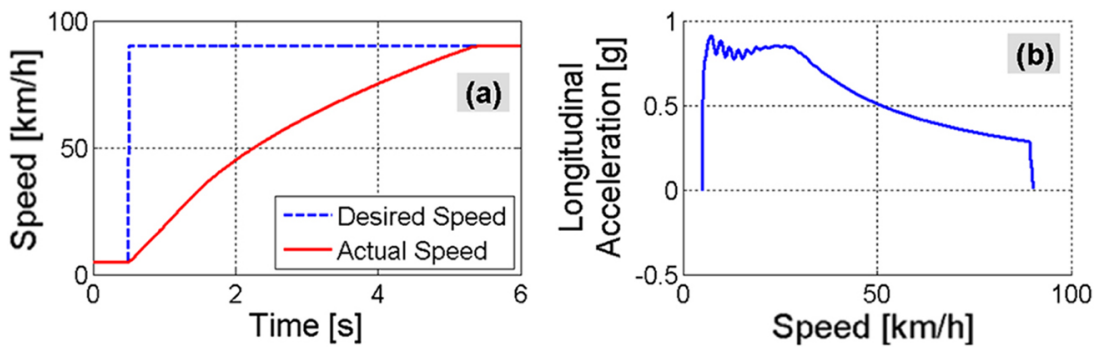

Figure 10. (a) Vehicle speed and (b) vehicle longitudinal acceleration versus forward speed during the straight-line acceleration maneuver

Figure 11 illustrates the slip ratio of each tire during the straight-line acceleration maneuver. The plots shown in Figure 11 clearly indicate that the slip controllers on the front wheels have limited the tire slips after the start of acceleration up to about 1 second, where tire spin-out would have otherwise occurred due to the availability of high motor torques and the dynamic weight shift to the rear axle. Moreover, the slip controllers on the rear wheels are activated for a short period of time ( 0.1 seconds) in order to generate the maximum possible traction force while preventing any tire spin-out. The activation of the slip controllers can also be verified by looking at the motor torque histories in Figure 12. The required torque from the driver model $\left(\mathrm{T}_{\text {Driver,req }}\right)$ is modified by the slip controllers $\left(T_{S C i, r e q}\right)$ such that, during a period of about 0.1 seconds after the start of the acceleration, the rate of change of each motor torque is limited by its respective slip controller to prevent spin-out. The slip controllers on the front wheels have continued limiting the motor torques up to about 1.3 seconds of the simulation, at which point the maximum motor torques are automatically reduced due to the induction voltages and magnetization losses that occur at higher motor speeds. On the rear wheels, however, the actual torque of the motors is restricted by the maximum torque limit, not by the slip controllers. Moreover, due to the shifting of weight to the rear axle of the vehicle, the traction potentials of the rear tires have increased, thereby preventing these tires from spinning out. Note that the oscillatory behavior of the slip ratios of the rear tires in the first second of the simulation is caused by the tire model and not the controllers. Notice that the Pacejka 2002 tire model is used in this work, which is not very suitable for low speeds and ABS braking control applications. However, it was the best tire model that was available for this work.

The second maneuver used to evaluate the performance of the slip control design is a straight-line braking test. In this test, the driver intends to stop the AUTO21EV from a maximum speed of $80 \mathrm{~km} / \mathrm{h}$ in an emergency braking situation. Figure 13-a indicates that the braking distance is about 39.7 meters, which is a very impressive result considering the regulations on braking systems for passenger vehicles in the European Union (EU). As stated in the EU directives and regulations for braking systems, the braking distance of passenger-type vehicles must be less than 50.7 meters for an initial test speed of $80 \mathrm{~km} / \mathrm{h}$ [Bos07]. It takes about 4 seconds to bring the vehicle to a final speed of 5 $\mathrm{km} / \mathrm{h}$ (Figure 13-b), during which time none of the tires lock up. Note that the vehicle speed is only reduced to $5 \mathrm{~km} / \mathrm{h}$ due to the instability of the Pacejka tire model at low speeds. Figure 13-c indicates that a maximum deceleration of $0.82 \mathrm{~g}$ is achievable at speeds lower than $45 \mathrm{~km} / \mathrm{h}$. These results confirm that the proposed slip controller is capable of replacing the conventional brake system in the AUTO21EV. 

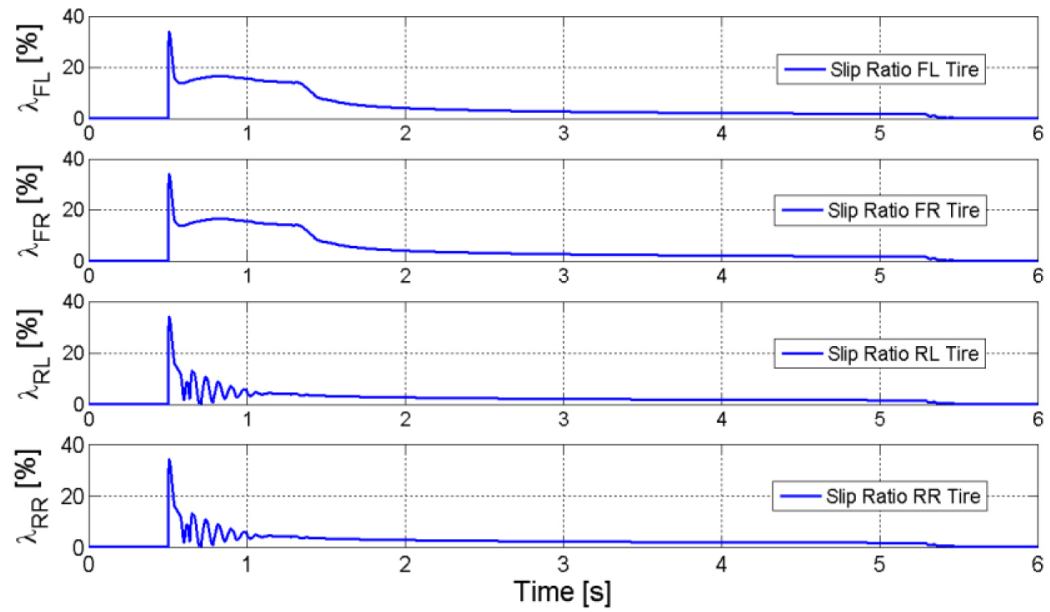

Figure 11. Tire slip ratios during the straight-line acceleration maneuver

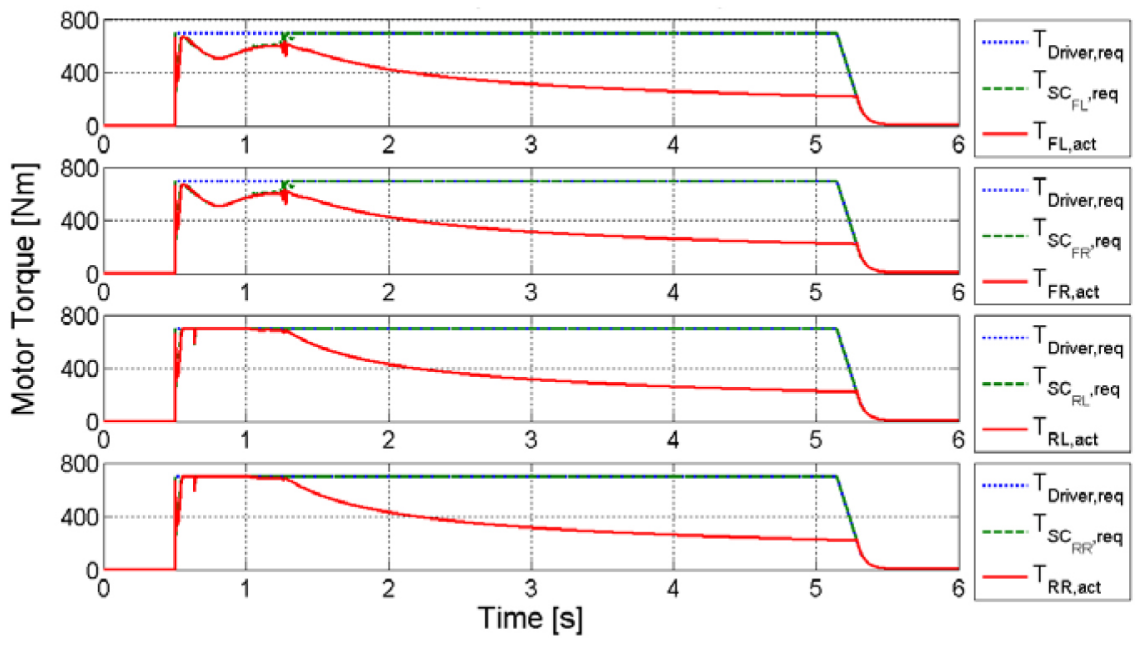

Figure 12. Motor torques during the straight-line acceleration maneuver

In other words, the in-wheel motors are capable of taking over the entire functionality of a conventional brake system for the entire speed range. As a fail-safe back-up, however, a redundant hand-brake system must be installed in the AUTO21EV.

As illustrated in Figure 14, the slip controllers are only activated on the rear tires at about 1.4 seconds, where tire lock-up would have otherwise occurred due to the dynamic weight shift to the front axle and higher available braking torques at lower speeds. This control effort is also apparent in Figure 15, in which the motor torques at the rear wheels are shown to be restricted to about $500 \mathrm{Nm}$, while the in-wheel motors on the front axle are permitted to apply the maximum torque of $700 \mathrm{Nm}$. In addition, since the slip controllers prevent any tire lockup, there is no need to introduce an extra braking force distribution technique, as is common in conventional brake systems. As mentioned earlier, the rapid oscillations in the slip ratio plots that occur after the third second of the simulation (when the vehicle speed is about 10 $\mathrm{km} / \mathrm{h}$ ) are caused by the tire model and not the controllers.

The third test for the fuzzy slip controller is performed on a $\mu$-split road, where the road is dry on the right side and icy on the left side. In this test, the driver holds the steering wheel fixed and accelerates the vehicle in a straight line from an initial speed of $10 \mathrm{~km} / \mathrm{h}$. The road is considered to be dry before $\mathrm{x}=15 \mathrm{~m}$ and after $\mathrm{x}=25 \mathrm{~m}$. As shown in Figure 16, a black ice patch is present on the left side of the road for $15 \mathrm{~m}$ $<\mathrm{x}<25 \mathrm{~m}$. Although the intention of the driver is to travel in a straight line, the car is pushed to the left side of the road due to the asymmetrical traction forces on the left and right sides of the vehicle. In order to keep the vehicle on the road, this side-pushing effect must be corrected either through a counter-steering input from the driver or by an active stability control system. Note that the slip control system has done its job by maximizing the available acceleration.

Figure 17 illustrates the tire slips of the vehicle during this acceleration maneuver. The slip controllers have limited the 


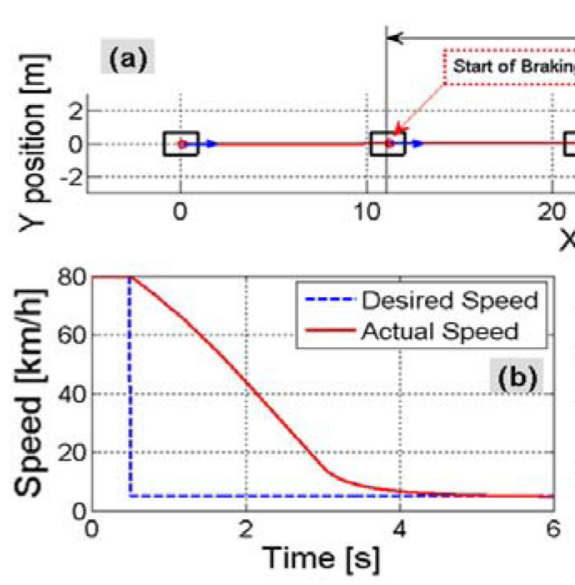

Braking Distance $=39.68 \mathrm{~m}$
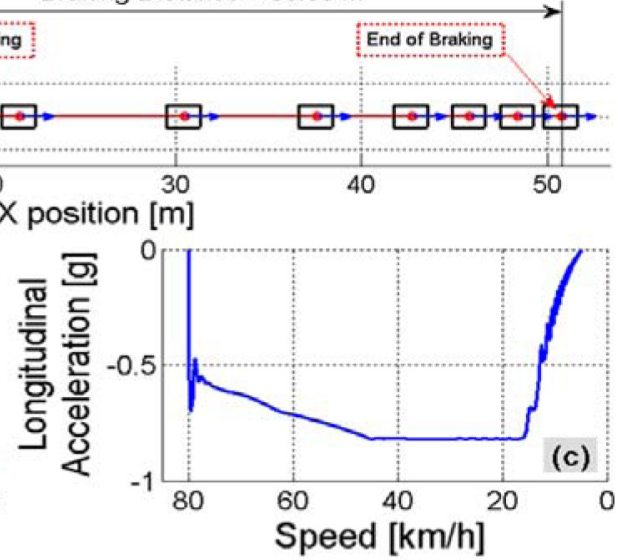

Figure 13. (a) Braking distance, (b) vehicle speed, and (c) vehicle longitudinal deceleration versus forward speed during the straight-line braking test

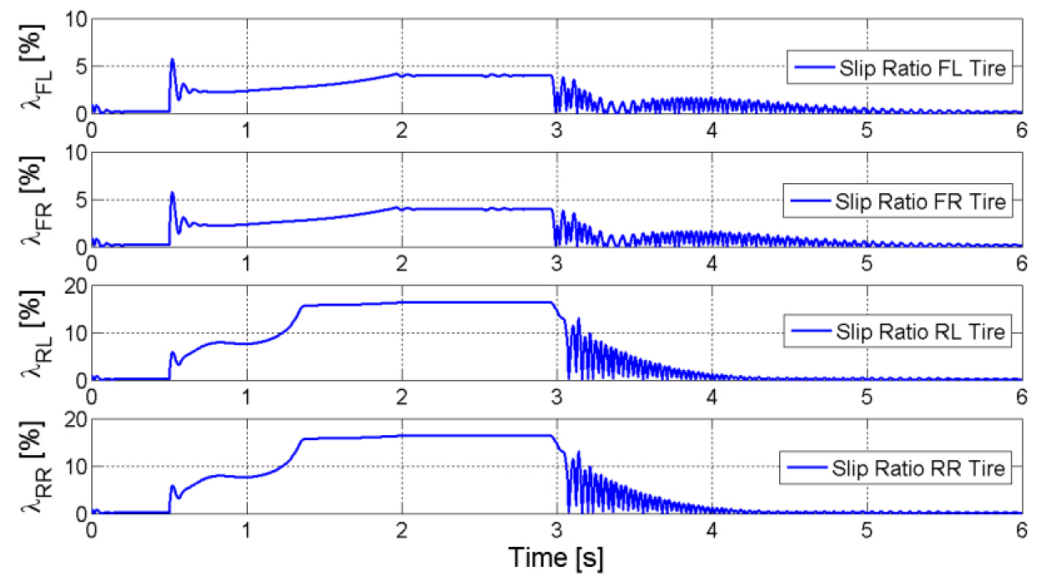

Figure 14. Tire slip ratios during the straight-line braking maneuver

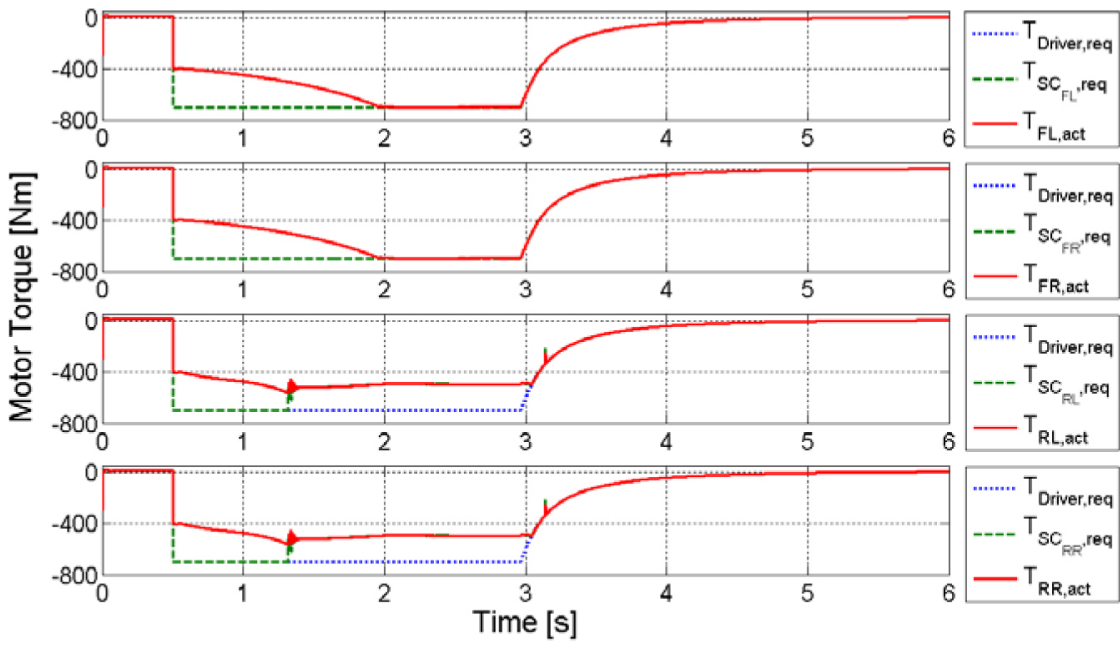

Figure 15. Motor torques during the straight-line braking maneuver 


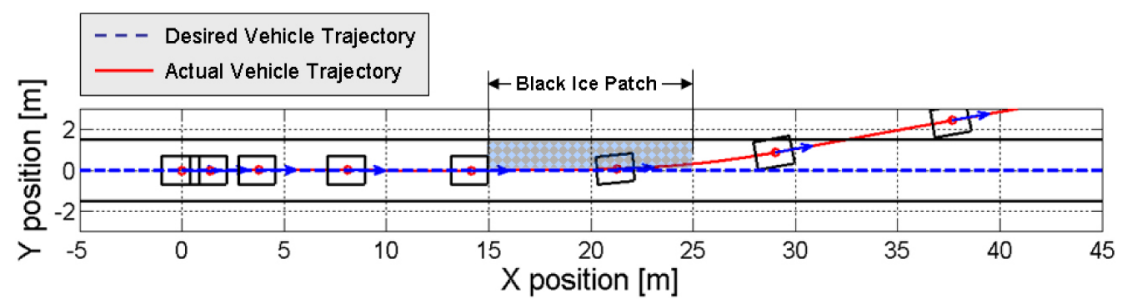

Figure 16. Vehicle trajectory when accelerating on a $\mu$-split road
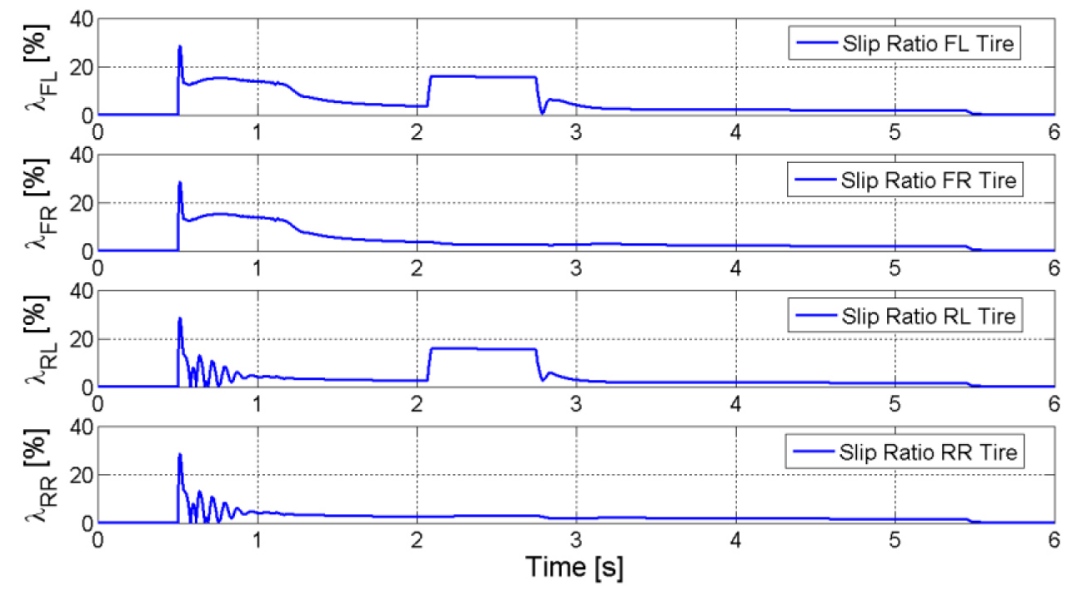

Figure 17. Tire slip ratios during the straight-line acceleration maneuver on a $\mu$-split road

tire slips on the front axle at the beginning of the acceleration, where tire spin-out would have occurred due to the available high motor torques and the dynamic weight shift to the rear axle. In addition, the slip controllers on the left side of the vehicle are activated when the vehicle drives over the black ice patch, thereby preventing tire spin-out while still generating the maximum possible traction force on the ice patch. As shown in Figure 18, the motor torques on the front wheels are limited by the slip controllers for about 0.6 seconds after the start of the acceleration. When driving over the black ice patch, the motor torques on the left side of the vehicle are reduced to about $40 \mathrm{Nm}$ to avoid tire spin-out.

The final test for the fuzzy slip controller is braking on a $\mu$-split road, which is a very critical test since the vehicle will experience severe instability if the driver does not react immediately to correct the course of the vehicle. In this test, the driver holds the steering wheel fixed and attempts to stop the vehicle in an emergency braking situation from $80 \mathrm{~km} / \mathrm{h}$ on a road that has a black ice patch on the left side for $15 \mathrm{~m}<$ $\mathrm{x}<25 \mathrm{~m}$. As illustrated in Figure 19, the vehicle is pushed to the right side of the road due to the asymmetrical braking forces on the left and right sides of the vehicle. More important is the fact that these asymmetrical braking forces are high enough to turn the vehicle around its vertical axis. In order to avoid such a dangerous situation, a driver must correct the course of the vehicle through a sequence of steering corrections based on the vehicle response, which is a very difficult task for an average driver. Although the slip controller has done its job to maximize the braking forces, further control is needed to maintain a safe trajectory.

As shown in Figure 20, the slip controllers on the left side of the vehicle have limited the tire slips when driving over the $\mu$-split portion of the road, which occurs between 0.7 and 1.2 seconds after the start of the simulation. The rear-right tire will also begin experiencing a lockup situation due to the shifting vehicle weight and a high braking torque at around 1.1 seconds, which is prevented by the rear-right slip controller. Furthermore, since the vehicle starts to turn around its vertical axis, large lateral forces are generated on all tires, which simultaneously reduce the braking force potential on all four tires. This yawing motion explains why the front-left, front-right, rear-left, and rear-right slip controllers are becoming active at around 1.95, 1.4, 1.6, and 1.1 seconds, respectively, to prevent tire lockup. The activation of the slip controllers is also confirmed by Figure 21, which illustrates the motor torques. Note that, due to the vehicle spin occurring in this test, only the meaningful range of data has been plotted in Figures 20 and 21 . 


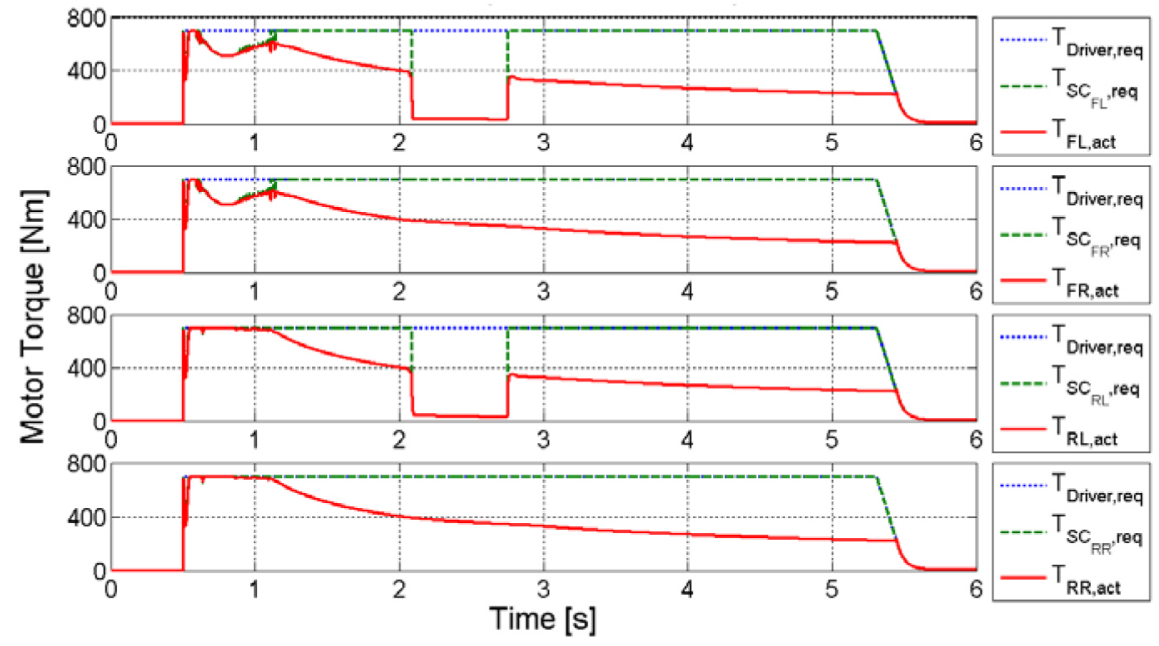

Figure 18. Motor torques during the straight-line acceleration maneuver on a $\mu$-split road

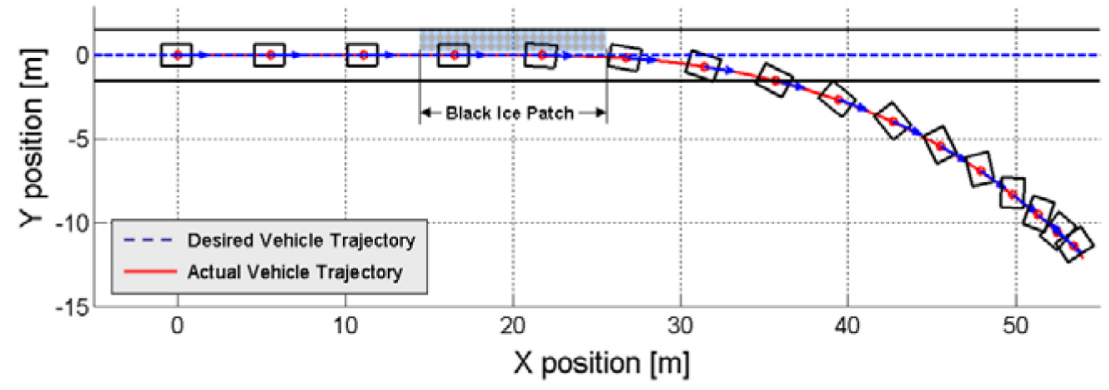

Figure 19. Vehicle trajectory when braking on a $\mu$-split road
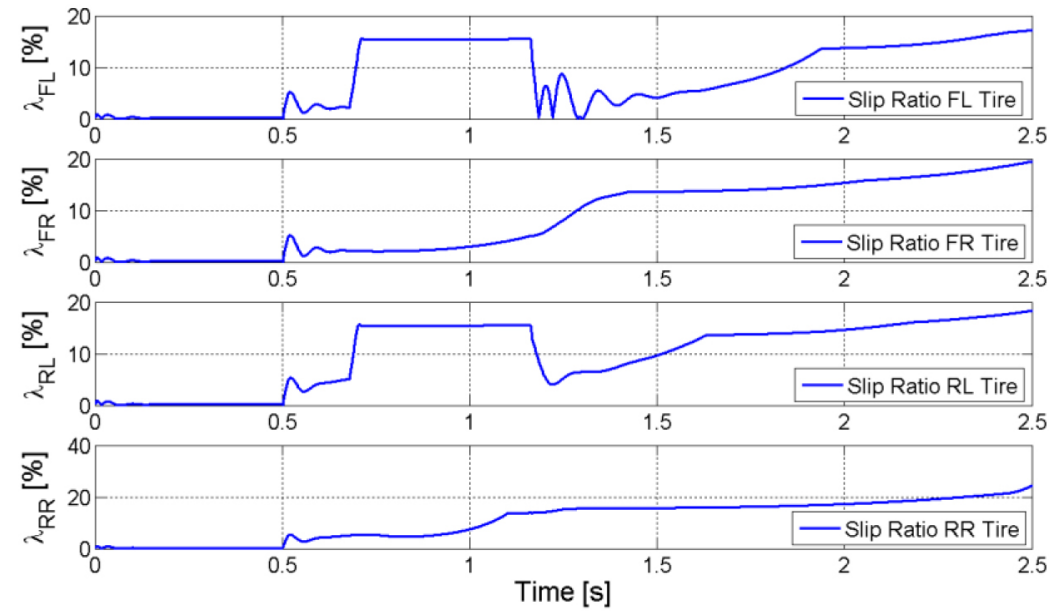

Figure 20. Tire slip ratios during the straight-line braking maneuver on a $\mu$-split road 


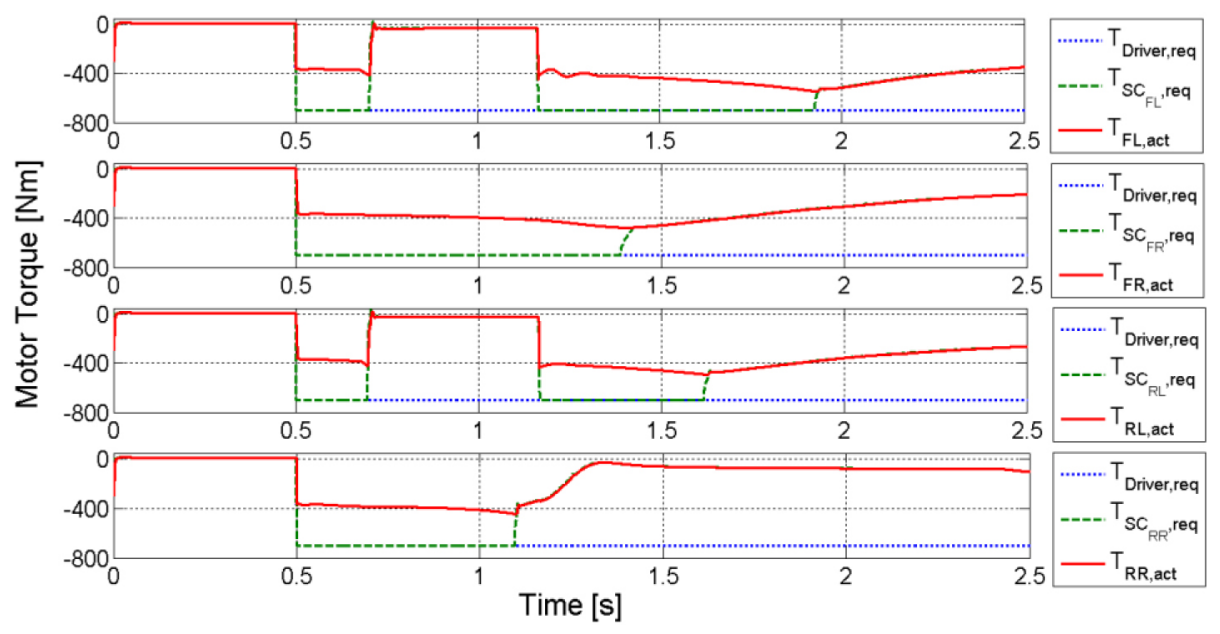

Figure 21. Motor torques during the straight-line braking maneuver on a $\mu$-split road

\section{SLIP CONTROL SYSTEM TESTS USING DRIVING SIMULATOR}

A hardware-in-the-loop (HIL) and operator-in-the-loop (OIL) driving simulator has been used to further evaluate the effectiveness of the proposed fuzzy slip controller. HIL simulation refers to the replacement of one or more components of a software model with the analogous hardware component, which communicates with the remaining elements of the software model throughout the simulation. An OIL simulation is similar, except that a human user provides some of the system inputs and observes or otherwise senses some of the system outputs during the simulation. Among the benefits of HIL simulation is its ability to replace preliminary field tests with safer, faster, and more rigorous automated tests. In addition, extreme or unusual situations can be simulated at will and replicated precisely, enabling the repeated simulation of cold-start engine tests in the summer, for example [Kri07]. It is for these reasons that HIL testing has continued to increase in popularity.

The driving simulator used in this work is shown in Figure 22, and involves the synchronized operation of several pieces of specialized hardware. The vehicle model, in-wheel motor models, and advanced slip controllers have been implemented on a quad-core Peripheral Component Interconnect (PCI) Extensions for Instrumentation (PXI) system from National Instruments, which uses the Laboratory Virtual Instrument Engineering Workbench (LabVIEW) RT real-time operating system to maintain precise timing during the simulation. Due to the amount of computation involved, a vehicle model with a torque driver applied to each wheel has been implemented on one Central Processing Unit (CPU) core of the quad-core PXI system, and the four in-wheel motor models are executed on a separate core. The advanced slip controllers are run on another CPU core, receiving sensor signals from the vehicle model and broadcasting control signals at regular intervals. A Windows-based laptop running LabVIEW communicates with the PXI system over Ethernet throughout the simulation. In addition to generating graphical feedback, the laptop must receive universal serial bus (USB) interrupts generated by the steering wheel and pedals, and send the relevant information to the PXI system for use in the simulation. The controllers in the driving simulator are evaluated using the same maneuvers as before.

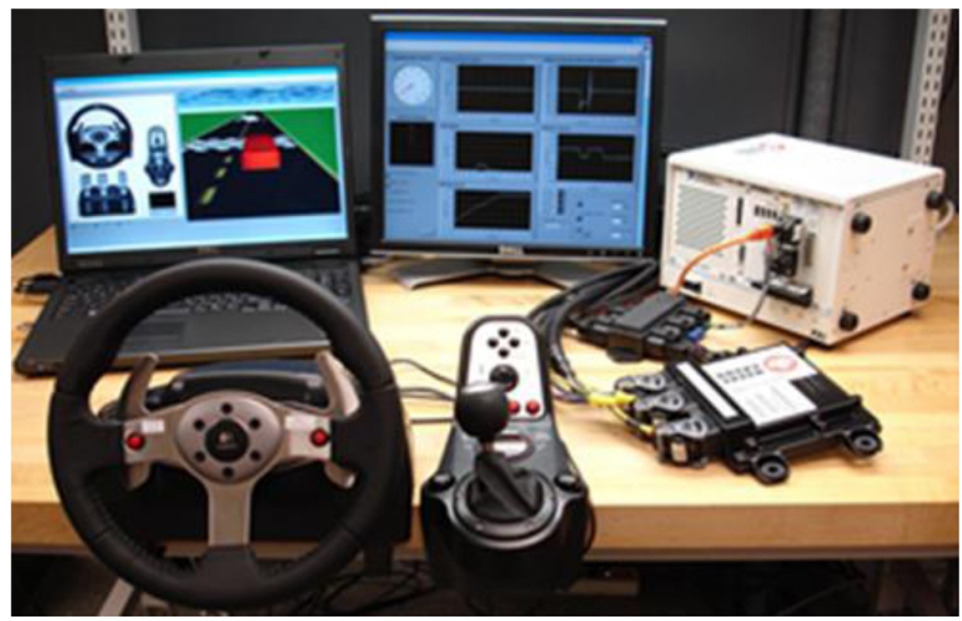

Figure 22. Hardware- and operator-in-the-loop driving simulator equipment 
Four maneuvers are used to test the performance of the slip control system. First, the vehicle is accelerated in a straight line from $5 \mathrm{~km} / \mathrm{h}$ to $90 \mathrm{~km} / \mathrm{h}$ on a dry road. The acceleration begins at 0.5 seconds, and the vehicle reaches its maximum speed in about 5 seconds (Figure 23). As shown in $\underline{\text { Figures } 24}$ and $\underline{25}$, the slip controllers have limited the motor torques so as to prevent tire spin-out while still generating the maximum possible traction force. These figures are analogous to Figures 11 and $\underline{12}$ above, and are in very close agreement. The slight differences can be attributed to the fact that the simulation in the driving simulator is distributed over several CPU cores, which introduces a small amount of lag between calculating control signals and applying them to the vehicle model.

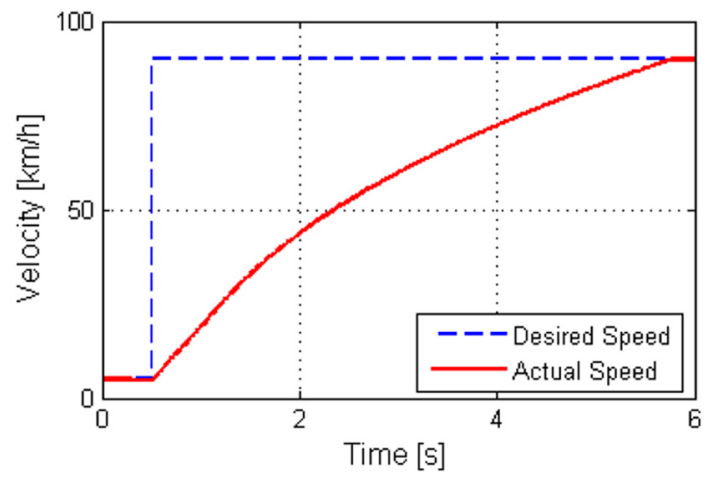

Figure 23. Vehicle speed during the straight-line acceleration maneuver
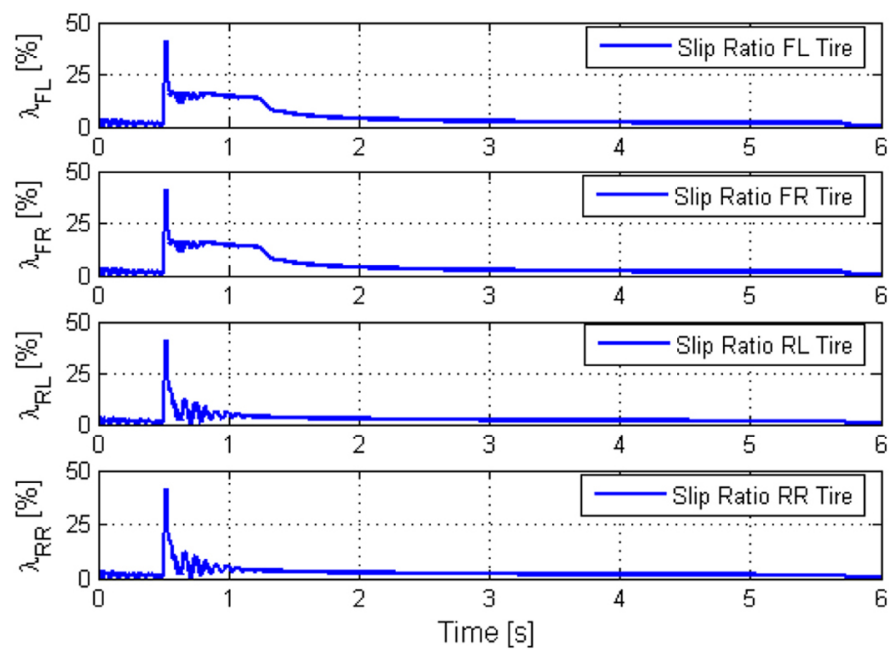

Figure 24. Tire slip ratios during the straight-line acceleration maneuver

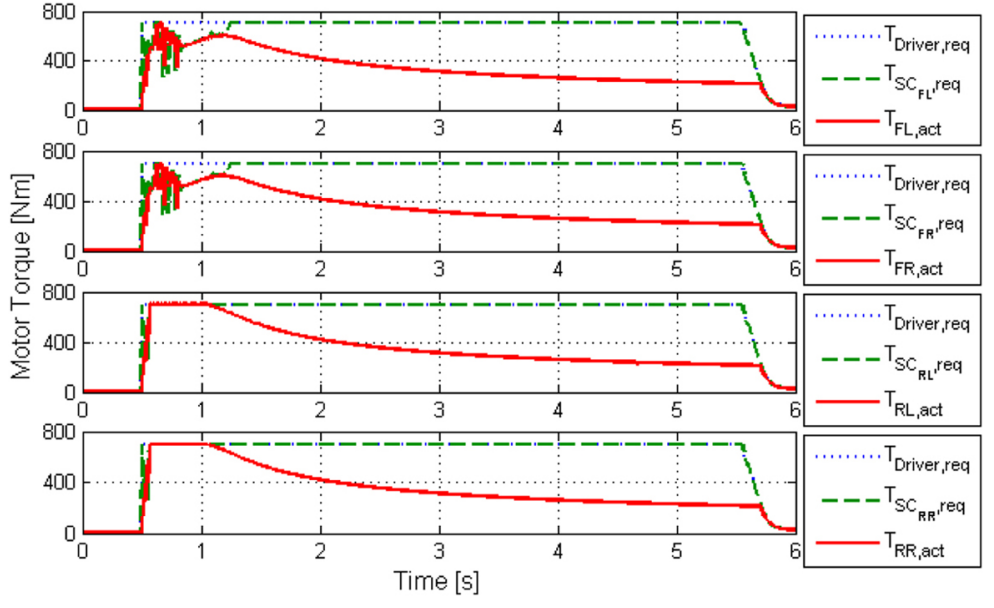

Figure 25. Motor torques during the straight-line acceleration maneuver

The second maneuver used to evaluate the performance of the slip controllers is a straight-line braking test, in which the brakes are applied aggressively from an initial speed of 80 $\mathrm{km} / \mathrm{h}$. Once again, due to the instability of the tire model at low velocities, the vehicle speed is only reduced to $5 \mathrm{~km} / \mathrm{h}$. The braking distance is about 40 meters and takes about 4 seconds (Figure 26), which agrees with the previous results. The slip ratios and motor torques shown in Figure 27 and $\underline{\text { Figure } 28}$ agree with those shown in Figures 14 and $\underline{15}$, respectively.

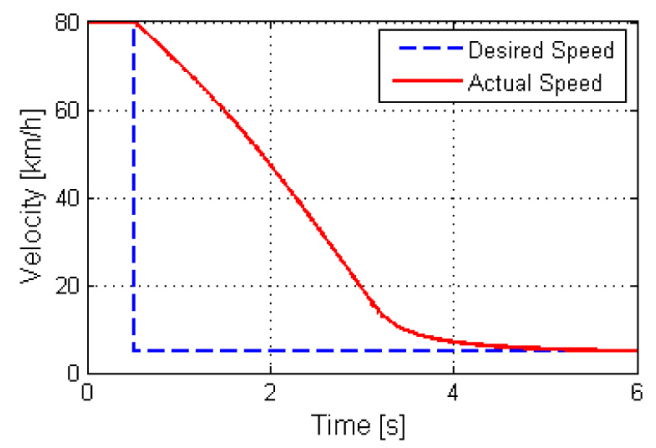

Figure 26. Vehicle speed during the straight-line braking maneuver

The third test is identical to the straight-line acceleration maneuver, but is performed on the $\mu$-split road described above, and the initial velocity of the vehicle is $10 \mathrm{~km} / \mathrm{h}$. As shown in Figure 29, the slip controllers on the left side of the vehicle are activated when the left tires are driving on the ice patch, preventing tire spin-out while still generating the maximum possible traction force. The motor torque plots shown in Figure 30 clearly indicate the reduction in torque on the left wheels when driving over the ice patch. These results agree with those shown in Figures 17 and $\underline{18}$ above. 

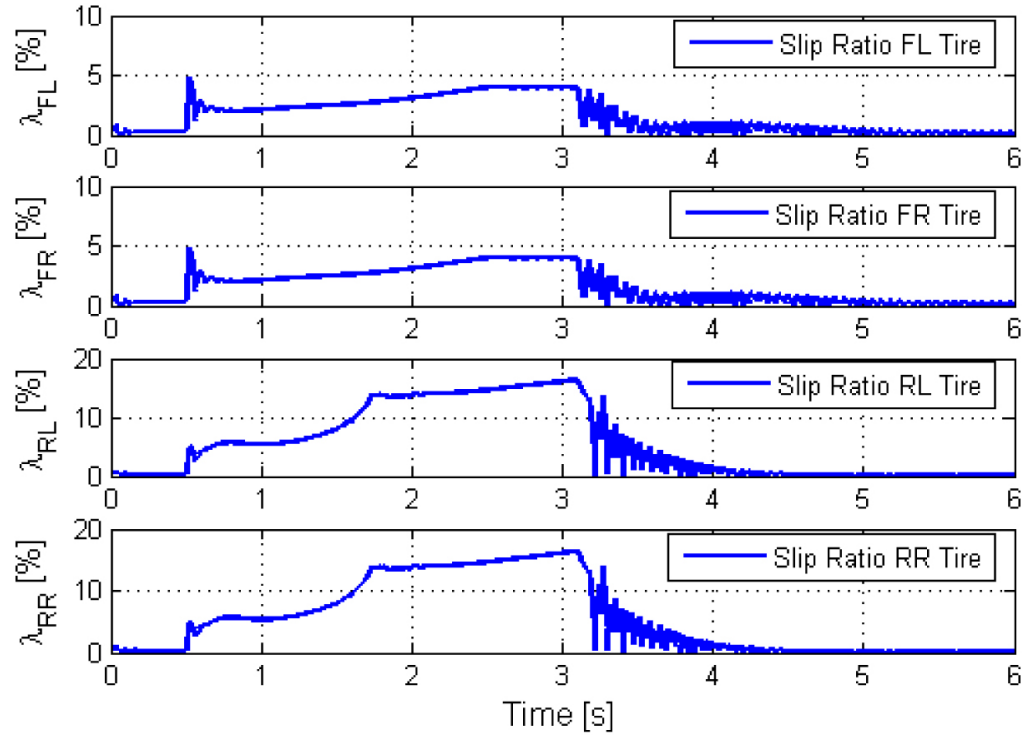

Figure 27. Tire slip ratios during the straight-line braking maneuver
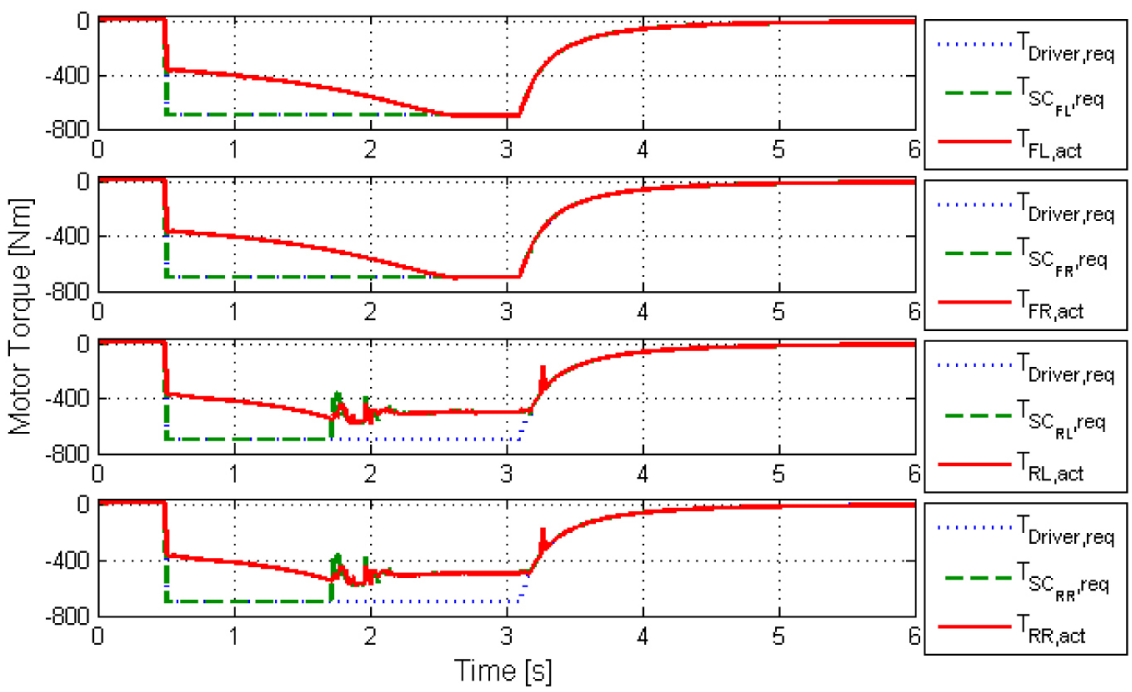

Figure 28. Motor torques during the straight-line braking maneuver
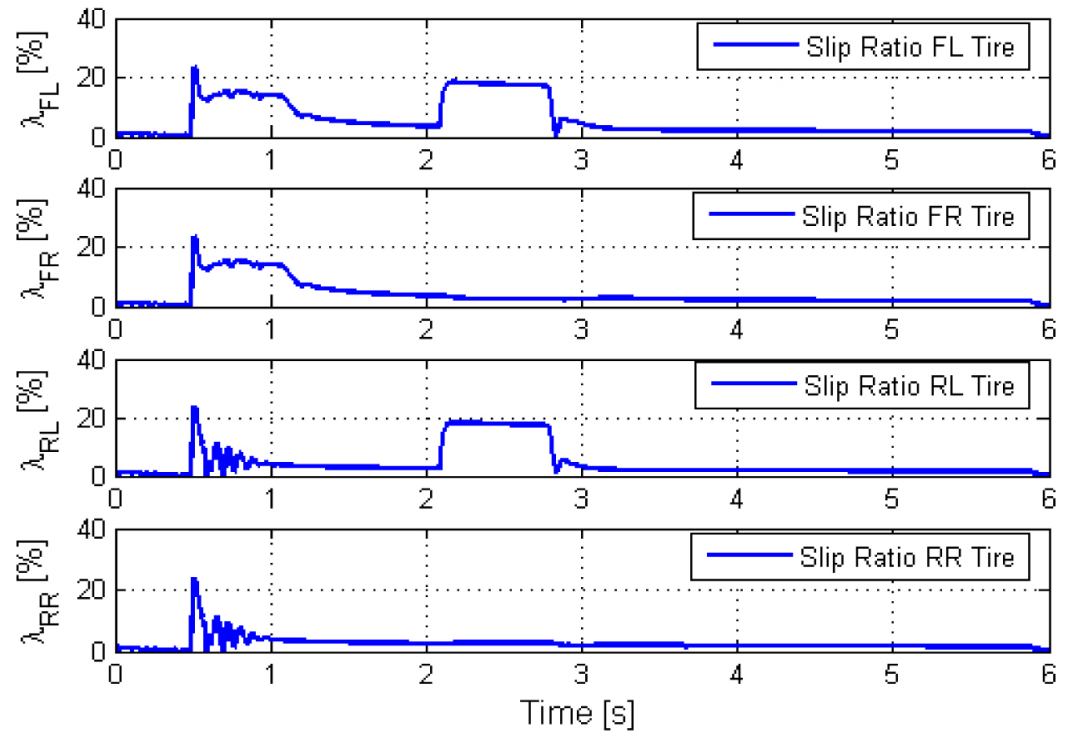

Figure 29. Tire slip ratios during the straight-line acceleration maneuver on a $\mu$-split road 


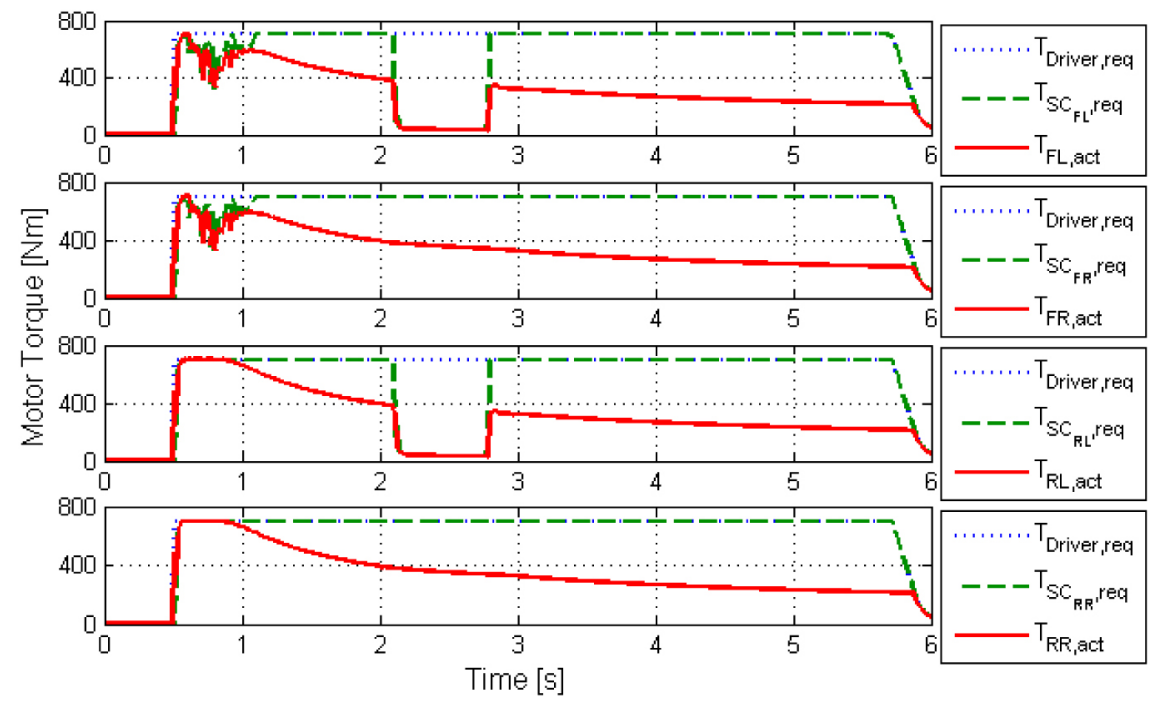

Figure 30. Motor torques during the straight-line acceleration maneuver on a $\mu$-split road
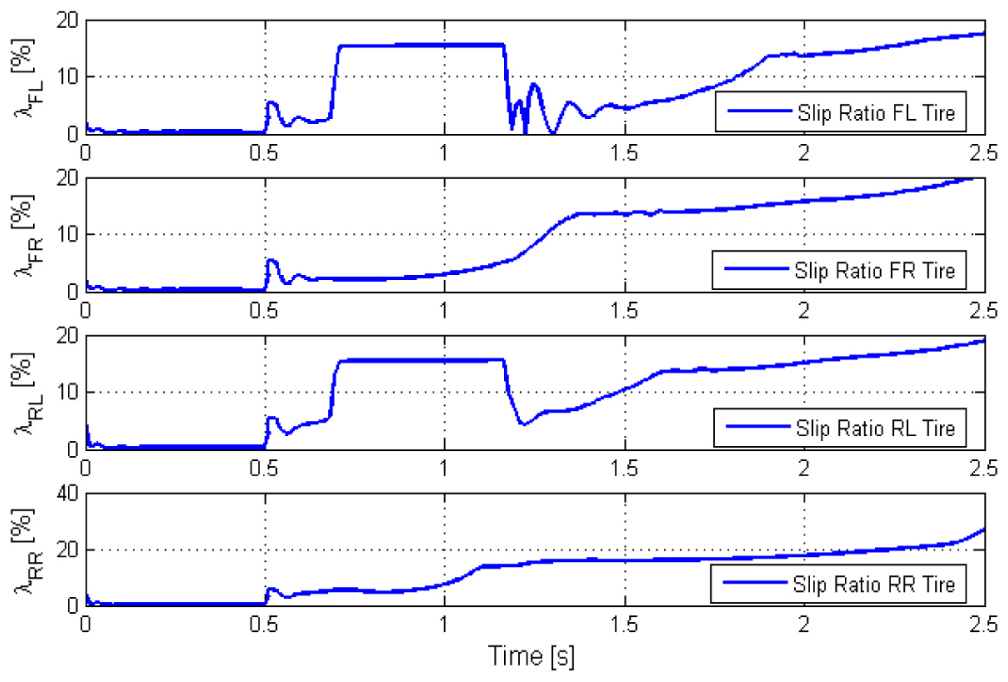

Figure 31. Tire slip ratios during the straight-line braking maneuver on a $\mu$-split road

The fourth and final test used to evaluate the slip control system is identical to the straight-line braking maneuver, but is performed on a $\mu$-split road. The tire slip ratios and motor torques are shown in Figures 31 and $\underline{32}$, respectively, which agree with Figures 20 and $\underline{21}$ above. Again, note that the asymmetrical braking forces cause the vehicle to yaw considerably when no corrective steering input is provided. 


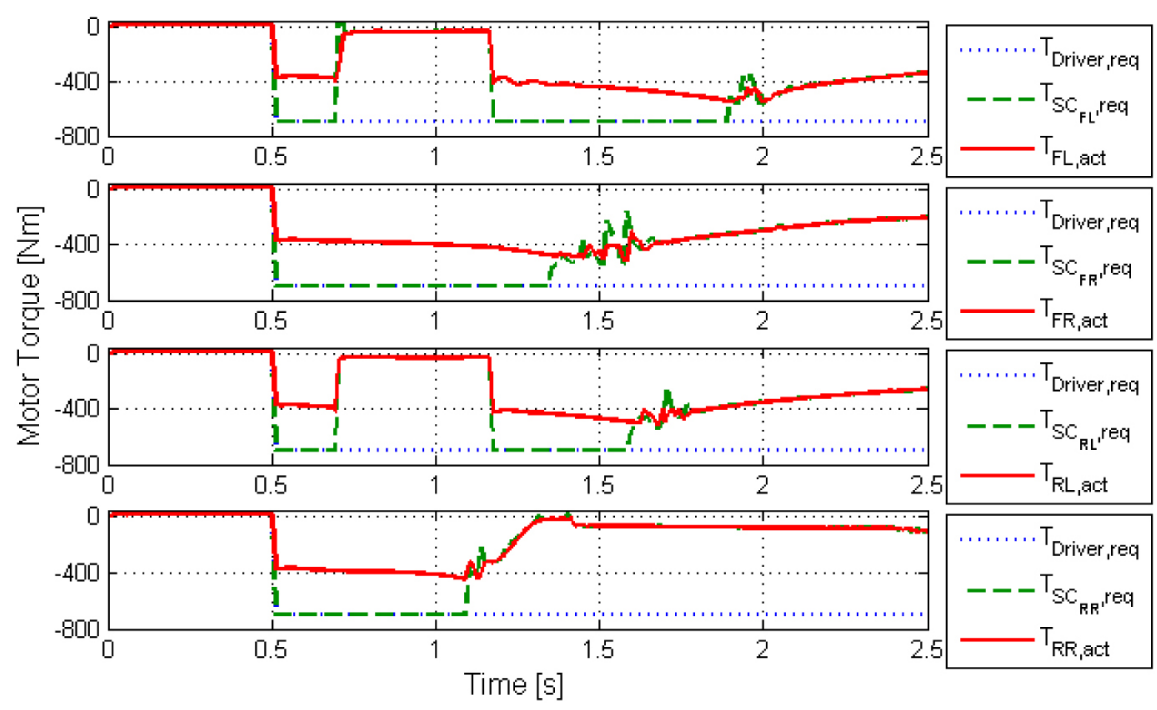

Figure 32. Motor torques during the straight-line braking maneuver on a $\mu$-split road

\section{CONCLUSION}

In this work, an advanced fuzzy slip controller is developed for the AUTO21EV, an electric vehicle model with four direct-drive in-wheel motors and an active steering system, which combines the functionalities of an ABS, a TCS, and the brake system of the vehicle. Since the developed fuzzy slip controller is able to control the slip ratio of all four wheels in all driving conditions, thereby realizing the most advanced All-Wheel-Drive system. The developed fuzzy slip controller is based on a chassis platform that has four individual electric drives, the reaction time of this slip controller is much faster than that of any other conventional slip control system based on a hydraulic brake system or internal combustion engine. In addition, the developed slip controller can also perform like the vehicle's conventional braking system. The effectiveness and potential of the fuzzy slip controller are examined via different standard test maneuvers, and its performance is confirmed in the simulation environment. As the final evaluation step, a hardware- and operator-in-the-loop driving simulator has been developed, in which the AUTO21EV vehicle model and the advanced slip control system are running in real-time on separate CPU cores, and receiving the steering wheel and braking or acceleration pedal signals from a real driver. The results from the driving simulator indicate the excellent performance of the advanced slip controller in different driving maneuvers.

\section{ACKNOWLEDGMENTS}

Funding for this work was provided by the Natural Sciences and Engineering Research Council of Canada (NSERC) and a grant from AUTO21, a Canadian Network of Centres of Excellence.

\section{REFERENCES}

- [Ack99] Ackermann, J., Odenthal, D., and Bünte, T.: "Advantages of active steering for vehicle dynamics control", 32nd International Symposium on Automotive Technology and Automation, Vienna, pp. 263-270, 1999.

- [Alb96] Alberti, V. and Babbel, E.: "Improved driving stability by active braking of the individual wheels", Proceedings of the International Symposium on Advanced Vehicle Control, Aachen, pp. 717-732, 1996

- [Bei00] Beiker, S.: Improving the Vehicle Dynamics Behavior through Integrated Control Systems, ("Verbesserungsmoeglichkeiten des Fahrverhaltens von Pkw durch zusammenwirkende Regelsysteme"), Ph.D. Dissertation, Technical University of Braunschweig, Germany, 2000.

- $\quad$ [Blu04] Blundell, M. and Harty, D., "The Multibody Systems Approach to Vehicle Dynamics," SAE International and Elsevier, Warrendale, PA, ISBN 978-0-7680-1496-9, 2004.

- [Bos07] Bosch Automotive Handbook, 7th edition, Robert Bosch GmbH, Plochingen, 2007.

- [Bur04] Burton, D., Delaney, A., Newstead, S., Logan, D., and Fildes, B.: "Effectiveness of ABS and vehicle stability control systems", Royal Automobile Club of Victoria (RACV) Ltd., Report Number 04/01, April 2004

- [Bur93] Burckhardt, M.: Chassis and Suspension Design: Slip Control Systems (Fahrwerktechnik: Radschlupfregelsysteme), Vogelverlag, Wuerzburg, 1993.

- [Dur03] Durali, M. and Bahramzadeh, Y.: "Vehicle Stability Improvement Using Fuzzy Controller and Neural-Network Slip Angle Observer," SAE Technical Paper 2003-01-2883, 2003, doi: 10.4271/2003-01-2883.

- $\quad$ [Hor04] Hori, Y.: "Future vehicle driven by electricity and control research on four wheel motored UOT Electric March II", IEEE Transactions on Industrial Electronics, 51(5), pp. 954-962, 2004.

- [Kar04] Karray, F.O. and de Silva, C.: Soft Computing and Intelligent Systems Design, Pearson Education Limited, 2004.

- $\quad$ Kie05] Kiencke, U. and Nielsen, L.: Automotive Control Systems for Engine, Driveline, and Vehicle, 2nd edition, Springer, 2005.

- [Kri07] Krisp, H., Lamberg, K., and Leinfellner, R., "Automated RealTime Testing of Electronic Control Units," SAE Technical Paper 2007-01-0504, 2007, doi:10.4271/2007-01-0504.

- $\quad$ [Mar02-a] Marshek, K., Cuderman, J.II, and Johnson, M., "Performance of Anti-Lock Braking System Equipped Passenger Vehicles - Part I: Braking as a Function of Brake Pedal Application Force," SAE Technical Paper 2002-01-0304, 2002, doi:10.4271/2002-01-0304.

- $\quad$ [Mar02-b] Marshek, K., Cuderman, J.II, and Johnson, M., "Performance of Anti-Lock Braking System Equipped Passenger Vehicles - Part II: Braking as a Function of Initial Vehicle Speed in Braking Maneuver,' SAE Technical Paper 2002-01-0307, 2002, doi:10.4271/2002-01-0307. 
. [Maz01] Mazzae, E.N., Garrott, W.R., Barickman, F., Ranney, T.A., and Snyder, A.: "NHTSA light vehicle anti-lock brake system research program-Task 7.1: Examination of ABS-related behavioral adaptation License plate study", DOT HS 809 430, November 2001.

- [Vel01] Veloso, F. and Fixson, F.: "Make-buy decisions in the auto industry: New perspectives on the role of the supplier as an innovator", Technological Forecasting and Social Change, 67, pp. 239-257, 2001.

. [Vog09] Vogt, H., Schmitke, C., Jalali, K., and McPhee, J.: "Unified modelling and real-time simulation of an electric vehicle", International Journal of Vehicle Autonomous Systems, 6(3-4), pp. 288-307, 2009.

- [Zan00]van Zanten, A.T.: "Bosch ESP Systems: 5 Years of Experience," SAE Technical Paper 2000-01-1633, 2000, doi:10.4271/2000-01-1633. 